Increasing order picking efficiency by integrating storage, batching, zone picking, and routing policy decisions

Peer-reviewed author version

VAN GILS, Teun; RAMAEKERS, Katrien; BRAEKERS, Kris; DEPAIRE, Benoit \& CARIS, An (2018) Increasing order picking efficiency by integrating storage, batching, zone picking, and routing policy decisions. In: International journal of production economics, 197, p. 243-261.

DOI: 10.1016/j.ijpe.2017.11.021

Handle: http://hdl.handle.net/1942/25634 


\title{
Increasing Order Picking Efficiency by Integrating Storage, Batching, Zone Picking, and Routing Policy Decisions
}

\author{
Teun van Gils ${ }^{\mathrm{a},}$, Katrien Ramaekers ${ }^{\mathrm{a}}$, Kris Braekers ${ }^{\mathrm{a}}$, Benoît Depaire ${ }^{\mathrm{b}}$, and An Caris ${ }^{\mathrm{a}}$ \\ ${ }^{a}$ Research Group Logistics, Hasselt University, Agoralaan Building D, 3590 Diepenbeek, Belgium \\ ${ }^{b}$ Research Group Business Informatics, Hasselt University, Agoralaan Building D, 3590 Diepenbeek, \\ Belgium \\ ${ }^{*}$ Corresponding author. Tel.: +32 11268789 \\ \{teun.vangils,katrien.ramaekers,kris.braekers,benoit.depaire,an.caris\}@uhasselt.be
}

November 30, 2017

\begin{abstract}
In order to differentiate from competitors in terms of customer service, warehouses accept late orders while providing delivery in a quick and timely way. This trend leads to a reduced time to pick an order. The main objectives of this research are to determine which order picking planning problems are related, to explain why and how individual planning problems are related, and to identify excellent performing policy combinations in several practical situations. Previous research shows contradictory findings on which planning problems are related. This paper is the first that explicitly analyzes and statistically proves the relations between storage, batching, zoning, and routing by a full factorial ANOVA. The value of combining the four main order picking planning problems is shown with a real-life case study as well as for multiple generalized warehouse designs. The results of the study clearly indicate that warehouses can achieve significant benefits by considering storage, batching, zone picking, and routing policies simultaneously. Awareness of the influence of an individual planning problem on the overall order picking performance is required to manage warehouse operations, resulting in a reduced order pick time.
\end{abstract}

Keywords: order picking; storage; order batching; zone picking; routing; warehouse policies interactions

\section{Introduction}

As customer markets globalize, supply chains increasingly depend on efficient and effective logistical systems to distribute products across a large geographical area. Warehouses are important parts of supply chains, and therefore warehouse operations need to work efficiently. A warehouse can be defined as a facility where activities of receiving, storage, order picking, and shipping are performed (Gu et al., 2007). 
Currently, literature mainly focuses on warehouse design (Dallari et al., 2009; Baker and Canessa, 2009; Marchet et al., 2015; Sprock et al., 2016) and individual warehouse planning problems, such as order batching or routing (Davarzani and Norrman, 2015; De Koster et al., 2007; Gu et al., 2007; Gong and De Koster, 2011), while concluding that these planning problems seem to be interdependent (Van Gils et al., 2017). This study focuses on planning problems related to order picking operations (i.e., the retrieval of stock keeping units from the warehouse in order to satisfy customer orders), more specifically on manual order picking processes, as these order picking systems account for $80 \%$ of all order picking systems in Western Europe (De Koster et al., 2007). Whether order picking is performed manually or automatically, high costs are related to this process (Marchet et al., 2015).

Order picking management, in particular organizing efficient and flexible order picking systems, has been identified as an important and complex planning operation (Marchet et al., 2015). In order to differentiate from competitors in terms of customer service, warehouses accept late orders from customers while providing delivery in a quick and timely way. By accepting late orders, the remaining time to pick an order is reduced. Furthermore, the order behavior of customers has changed from ordering few and large orders to many orders consisting of only a limited number of order lines. The changed order behavior can be ascribed to upcoming e-commerce markets and forces warehouses to handle a larger number of orders, while the time available for order picking has shortened (Van Gils et al., 2017).

Four operational planning problems can be distinguished with respect to order picking: storage location assignment, order batching, zone picking, and picker routing (Yu and De Koster, 2009). In this paper several policies (i.e., solution methods) for each planning problem are considered and potential interactions among these planning problems are investigated in order to manage order picking operations more efficiently. While the number of publications dealing with one specific order picking planning problem is extensive, only a limited number of researchers examine different planning problems simultaneously, even though the efficiency of different order picking planning problems seems to be interdependent (Van Gils et al., 2017; Davarzani and Norrman, 2015). The effect of zoning in combination with other order picking planning problems, such as storage, routing and batching, has received especially little research attention (Van Gils et al., 2017).

This paper investigates combinations of the four main operational order picking planning problems with the aim of fulfilling three research objectives. First, based on a simulation study, we aim to determine which planning problems are statistically significantly related and, consequently, which planning problems should be considered simultaneously. Second, if a relation is significant, this study analyzes why and how the individual planning problems of storage, batching, zoning and routing are related. Third, by analyzing combinations of storage, batching, zoning and routing, we aim to identify excellent performing policy combinations in several practical situations in order to improve overall order picking performance. Results of the study provide insights in how combining the four main order picking planning problems support new market developments (i.e., short time windows and a large number of small orders). 
To the best of our knowledge, this paper is the first that explicitly analyzes and statistically proves the relations between storage location assignment, order batching, zone picking and picker routing. Simulation experiments show the impact of combining order picking planning problems in a real-life warehouse as well as for more generic warehouse designs. Insights into the interactions between the four main order picking planning problems are provided by performing a full factorial analysis of variance (ANOVA). Furthermore, the study contributes to both practitioners and academia by explaining how the planning problems are related and formulating guidelines on which planning problem policies to combine in order to improve order picking activities.

The remainder of the paper is organized as follows. Section 2 is devoted to presenting the current state-of-the-art and formulating research hypotheses on how order picking planning problems are expected to be related. Section 3 introduces the experimental design and the assumptions linked to the case. The first two research objectives are fulfilled in Section 4 that provides the empirical results. Section 5 discusses the managerial implications of this study and summarizes excellent performing policy combinations that help to improve the overall order picking performance in several practical situations. Finally, Section 6 is devoted to the concluding remarks and future research directions.

\section{Literature Review}

This section introduces literature on combining storage, batching, zoning, and routing in a manual order picking warehouses. The four main order picking planning problems are discussed in Section 2.1. Section 2.2 is devoted to literature combining multiple order picking planning problems and formulating research hypotheses on the relation between these order picking planning problems.

\subsection{Order Picking Planning Problems}

Order picking as a warehouse function arises because goods are received in large volumes and customers order small volumes of different products. Each customer order is composed of one or more order lines, with every order line representing a single stock keeping unit (SKU) (De Koster et al., 2007). In order to manage order picking operations, warehouse managers are confronted with four order picking planning problems, in particular storage location assignment (i.e., determining the physical location at which incoming products are stored), order batching (i.e., rules defining which orders to combine in each pick tour), zone picking (i.e., dividing the order picking area into smaller zones and allowing order pickers to retrieve items of a single zone), and routing (i.e., sequencing the items on the pick list) (De Koster et al., 2007). Table 1 discusses multiple policies for each planning problem to organize operations in a manual (picker-to-part) order picking system.

The majority of studies improving order picking operations focus on either storage (e.g., Guo et al. (2016); Manzini 
Table 1: Overview of policies of the four main order picking planning problems

\begin{tabular}{|c|c|}
\hline & Description of order picking policies \\
\hline \multicolumn{2}{|c|}{ Storage (Guo et al., 2016; Yu et al., 2015) } \\
\hline $\begin{array}{l}\text { Random } \\
\text { Within-aisle } \\
\text { Across-aisle } \\
\text { Diagonal } \\
\text { Perimeter }\end{array}$ & $\begin{array}{l}\text { Storage locations for each SKU are selected randomly from all eligible empty locations. } \\
\text { SKUs in a single pick aisle belong to the same turnover based storage class. } \\
\text { Each storage class is located across several pick aisles. } \\
\text { Storage classes are located with respect to the distance to the depot. } \\
\text { Storage classes are located around the periphery of the warehouse. }\end{array}$ \\
\hline \multicolumn{2}{|c|}{ Batching (De Koster et al., 1999; Henn et al., 2012) } \\
\hline Priority rule based & $\begin{array}{l}\text { Orders are prioritized and assigned to pick lists based on their priority (e.g., first-come-first-served } \\
(\text { FCFS )). }\end{array}$ \\
\hline Seed based & $\begin{array}{l}\text { Generation of batches is done by selecting an initial seed order (e.g., select the smallest order), after } \\
\text { which unassigned customer orders are added to the seed order according to an order congruency rule } \\
\text { (e.g., add an order such that the number of additional pick locations is minimal). }\end{array}$ \\
\hline Savings based & $\begin{array}{l}\text { Pick lists are composed based on the distance savings that can be obtained by combining two or more } \\
\text { customer order into a single route. }\end{array}$ \\
\hline Metaheuristic & A set of guidelines to develop heuristic optimization algorithms for batching of orders. \\
\hline Exact algorithm & The order batching problem is solved to optimality using for example branch-and-bound. \\
\hline \multicolumn{2}{|c|}{ Zoning (Jane and Laih, 2005; Petersen, 2002) } \\
\hline $\begin{array}{l}\text { Product properties } \\
\text { assignment }\end{array}$ & Products are assigned to zones based on physical properties of products, such as size and weight. \\
\hline $\begin{array}{l}\text { Demand properties } \\
\text { assignment }\end{array}$ & $\begin{array}{l}\text { Products are assigned to zones based on product demand properties, such as customer type and order } \\
\text { frequency. }\end{array}$ \\
\hline \multicolumn{2}{|c|}{ Routing (Roodbergen and De Koster, 2001; Theys et al., 2010; Scholz et al., 2016) } \\
\hline $\begin{array}{l}\text { Aisle-by-aisle } \\
\text { Traversal }\end{array}$ & $\begin{array}{l}\text { Each order picker visits every pick aisle containing at least one pick location through the entire length. } \\
\text { Each order picker traverses every subaisle (i.e., the part of a pick aisle that is within one warehouse } \\
\text { block) containing at least one pick location through the entire length. }\end{array}$ \\
\hline Return & $\begin{array}{l}\text { Each order picker enters and leaves each pick aisle containing at least one pick location form the same } \\
\text { end. }\end{array}$ \\
\hline Midpoint & $\begin{array}{l}\text { Each order picker enters a pick aisle only as far as the midpoint of an aisle and returns to leave the } \\
\text { pick aisle from the same end. }\end{array}$ \\
\hline Largest gap & $\begin{array}{l}\text { Each order picker enters a pick aisle only as far as the start of the largest gap within an aisle and } \\
\text { returns to leave the pick aisle from the same end. The largest gap is defined as the maximum distance } \\
\text { between any two adjacent pick locations within a single aisle, or the maximum distance between an } \\
\text { aisle end and a pick location. }\end{array}$ \\
\hline Metaheuristic & A set of guidelines to develop heuristic optimization algorithms for routing order pickers. \\
\hline Exact algorithm & The order picker routing problem is solved to optimality using for example branch-and-bound. \\
\hline
\end{tabular}


et al. (2015); Yu et al. (2015)), batching (e.g., Gademann and Van de Velde (2005); Muter and Öncan (2015)), zoning (e.g., Ho and Lin (2017); Jane and Laih (2005); Petersen (2002)), or routing (e.g., Elbert et al. (2017); Scholz et al. (2016); Theys et al. (2010)), assuming all other decisions being given. The reader is referred to De Koster et al. (2007) and $\mathrm{Gu}$ et al. (2007) for an extensive overview of publications optimizing a single order picking planning problem.

\subsection{Combining Storage, Batching, Zoning, and Routing Planning Problems}

This section focuses on studies analyzing interactions among operational order picking planning problems (i.e., storage, batching, zoning, and routing), with the aim of summarizing which planning problem combinations have been investigated in literature and why certain interactions among planning problems are found to be significantly related. Interactions are defined as the joint effect that two or more planning problems have on a performance goal, which can be investigated by considering multiple policies (i.e., solution methods or techniques for organizing a planning problem) for each planning problem and analyzing the effect of these policies on the order picking performance (Van Gils et al., 2017). Table 2 gives an overview of studies analyzing combinations of order picking planning problems. Based on the findings of the literature, we formulate research hypotheses on the expected relation among the four main order picking planning problems.

Table 2: Previous research combining operational order picking planning problems

\begin{tabular}{|c|c|c|}
\hline & Significant relation & No significant relation \\
\hline Storage-batching & $\begin{array}{l}\text { Ho and Tseng (2006); Ho et al. (2008); Hsieh and } \\
\text { Tsai (2006); Petersen and Aase (2004); Ruben } \\
\text { and Jacobs (1999) }\end{array}$ & Chackelson et al. (2013) \\
\hline Batching-routing & $\begin{array}{l}\text { Chen et al. (2015); Cheng et al. (2015); Chack- } \\
\text { elson et al. (2013); Kulak et al. (2012); Petersen } \\
\text { and Aase (2004); Won and Olafsson (2005) }\end{array}$ & Ho and Tseng (2006); Ho et al. (2008) \\
\hline Batching-zoning & Petersen (2000); Yu and De Koster (2009) & - \\
\hline Routing-zoning & - & - \\
\hline
\end{tabular}

Articles analyzing the combination of storage location assignment and order batching are rather consistent about the statistical significance of the storage and batching relation (Ho and Tseng, 2006; Ho et al., 2008; Hsieh and Tsai, 2006; Petersen and Aase, 2004). The storage location assignment policy defines rules for assigning items to locations in the order picking area. The batching policy should take these item location rules into account while creating batches in order to efficiently manage the batching planning problem (Ruben and Jacobs, 1999). Therefore, Hypothesis 1 states that storage location assignment and order batching are related as the use of item location information while batching orders is expected to result in significant performance benefits.

Hypothesis 1 The joint effect of storage location assignment and order batching on order picking performance is 
significant.

In contrast to the storage-batching interaction, publications investigating the relation between storage location assignment and routing are less consistent about the significance of the storage location assignment and routing relation. In a limited factorial setting, in particular a limited number of analyzed policies, storage location assignment and routing are found to be unrelated (Chackelson et al., 2013; Ho and Tseng, 2006; Ho et al., 2008). However, other articles do find a statistically significant interaction between the storage and routing planning problems, both in single block warehouses (Manzini et al., 2007; Petersen and Schmenner, 1999), and in multiple block warehouses (Shqair et al., 2014; Theys et al., 2010). These studies take information about the location of fast moving products into account while composing order picker routes. Therefore, the efficiency of routing policies is expected to be strongly depending on the applied storage location assignment policy as indicated by Hypothesis 2.

Hypothesis 2 The joint effect of storage location assignment and picker routing on order picking performance is significant.

A large number of articles analyzing the combination of batching and routing policies reveal that these planning problems are unrelated (Ho and Tseng, 2006; Ho et al., 2008), while other studies do find significant performance benefits by combining batching and routing (Chackelson et al., 2013). Moreover, integrating the construction of routes while creating batches results in considerable performance benefits compared to solving the planning problems sequentially (Chen et al., 2015; Cheng et al., 2015; Kulak et al., 2012; Won and Olafsson, 2005). This can be explained by the fact that the performance of the created batch is mainly defined by the length of the constructed route. Therefore, Hypothesis 3 states that a significant interaction exists between the batching and routing planning problems.

Hypothesis 3 The joint effect of order batching and picker routing on order picking performance is significant.

Zone picking operations in combination with other order picking planning problems have received little research attention yet (Van Gils et al., 2017), despite of its importance in order picking system performance (Petersen, 2002). The relation between zone size and storage location assignment planning problems has been investigated, but studies show contradicting results about the significance of the relation between zone size and storage location assignment (De Koster et al., 2012; Petersen, 2002). As the size of the zone defines the number of aisles within each order picking zone, the zone size is expected to significantly influence the efficiency of the storage location assignment. Furthermore, the joint effect of zone assignment and storage location assignment has not been analyzed so far. Both zone assignment policies and storage location assignment policies impact the pick densities in the order picking area. Consequently, the 
zone picking planning problem and the storage location assignment planning problem are expected to be significantly related (Hypothesis 4).

Hypothesis 4 The joint effect of storage location assignment and zone picking on order picking performance is significant.

Just as the storage location assignment and zoning relation, research analyzing the relation between order batching and zoning is limited. By only comparing whether or not to batch (FCFS batching) and varying the number of zones, the batching and zoning problem are found to be interrelated (Petersen, 2000; Yu and De Koster, 2009). In case more sophisticated batching policies are used, the effect of zoning on the order picking performance is expected to reduce as these batching rules help order pickers to avoid traveling throughout the entire order picking area. Furthermore, storage zone assignment as well as batching impact the density of picking activities and, consequently, we expect the zone picking and batching planning problem to be strongly interrelated as stated in Hypothesis 5.

Hypothesis 5 The joint effect of order batching and zone picking on order picking performance is significant.

Finally, the joint effect of the zone picking and routing planning problems is currently unknown (Van Gils et al., 2017). As zoning decisions have substantial impact on the distribution of pick density across the order picking area, and the efficiency of routing policies is determined by the distribution of pick densities, we hypothesize that both planning problems will be significantly related (Hypothesis 6).

Hypothesis 6 The joint effect of zone picking and picker routing on order picking performance is significant.

In summary, several articles have analyzed a storage-batching, storage-routing and batching-routing. Whether interactions among these three planning problems exist or not, depends on the number of analyzed policies for each planning problem, as well as which policies have been evaluated. Most articles of Table 2 are limited to analyzing two or three policies for each planning problem. Furthermore, research evaluating the effect of zone picking on other order picking planning problems is scarce. To the best of our knowledge, this study is the first to analyze the interaction between the four main operational order picking planning problems. In order to evaluate the contradicting findings, a wide range of policies for each planning problem are included in the simulation experiments. Additionally, the effect of the number of zones and the storage zone assignment in relation with storage location assignment, order batching, and routing on the order picking efficiency is analyzed for the first time.

\section{Experimental Design}

The main objective of this research is to analyze and evaluate if, how and why order picking planning problems are related and which policy combinations result in the best overall order picking performance. Simultaneously analyzing 
storage location assignment, order batching, zone picking, and routing policies using a factorial design provides insights into the impact of each operational order picking planning problem on the overall performance, as well as into the relation among the order picking planning problems. The description and assumptions of the real-life case as well as the factor setting of the simulation experiments in the real-life warehouse are discussed in Section 3.1. In order to validate and generalize the results of the case study, Section 3.2 describes a second experimental factor setting that is used in addition to the experiments of the real-life case. Finally, Section 3.3 introduces the performance measures used to evaluate the joint effect of order picking planning problems.

\subsection{Experimental Design of Real-life Case Study}

In order to analyze the effect of combining storage, batching, zoning, and routing, real-life data are used. We use the case study of Van Gils et al. (2016) that is based on a large warehouse located in Belgium to show the practical relevance of integrating storage, batching, zone picking, and routing policy decisions. The warehouse stores approximately 90,000 SKUs on a surface of 30,000 square meter. All stored SKUs are rather homogeneous with respect to volume and weight, implicating that the sequence in which SKUs are retrieved from the storage locations is not restricted and all storage locations are equally sized. The warehouse delivers four customer types: each SKU belongs to a single customer type and orders consists of SKUs of a single customer type.

The warehouse under consideration is shown in Figure 1. The traditional multiple-block warehouse layout is frequently used in practice (Roodbergen, 2012), making results of the study easily transferable to other warehouses. Furthermore, cross aisles have proven to result in significantly efficiency benefits (Roodbergen and De Koster, 2001). The order picking area is divided into two warehouse blocks, each consisting of 16 pick aisles. The pick aisles are two-sided and wide enough for two-way travel. However, crossing the aisle is required in order to pick items from both sides of the same aisle, as the aisle width is $2.7 \mathrm{~m}$. The dimensions of the aisles, as well as the warehouse block configuration and the zone configuration (in case zone picking is applied) are shown on Figure 1.

The warehouse is fully manually operated in which strict order picking is currently applied. Products are assigned randomly to the storage locations. Customer orders are transformed into pick lists according to the FCFS rule. A sort-while-pick strategy is used, maintaining order integrity, so that no downstream sorting is required. The picking vehicle is able to sort 26 orders during a pick tour. Order pickers follow the aisle-by-aisle routing policy to retrieve all items on the pick list. Each picking tour starts and ends at the decentralized depot. The depot is marked as $D$ in the bottom left corner of Figure 1. The policy combination of random storage, FCFS order batching, strict order picking, and aisle-by-aisle routing is used as benchmark in order to evaluate other storage, batching, zoning, and routing policies. Choosing the optimal combination of different order picking policies is crucial for warehouse managers 


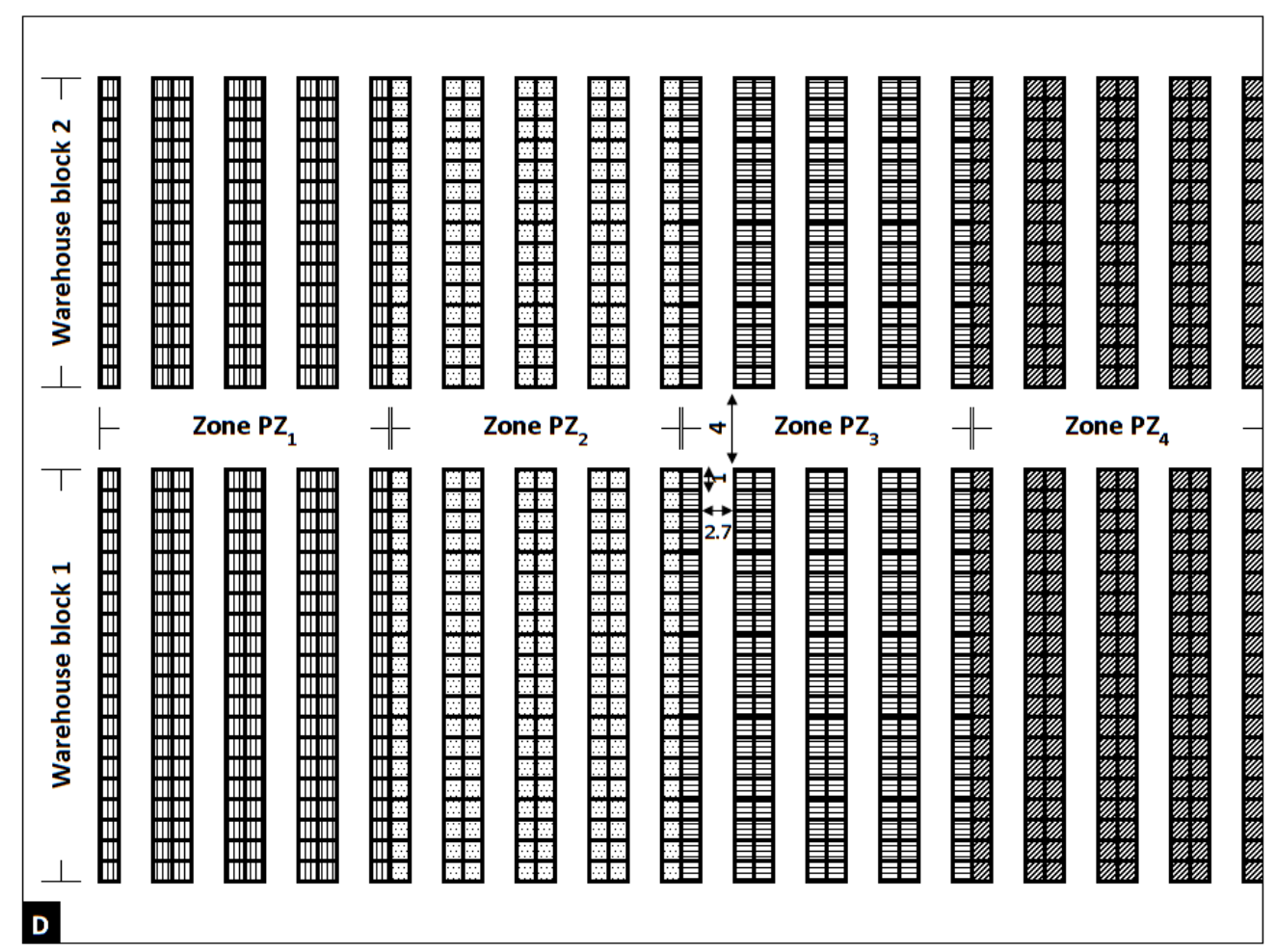

Figure 1: Warehouse layout.

in order to improve the overall order picking performance and consequently improving the service to customers.

In the experiments of this paper, a wide range of policies are evaluated: five different storage location assignment policies, three order batching policies, five zone picking policies, as well as five routing policies are analyzed. The four factors and their associated factor levels of the real-life case are summarized in Table 3. The baseline scenario of this experiment, indicated in italic in Table 3, corresponds to the current operation of the warehouse. In the simulation studies, policies that are widely used in practice (e.g., FCFS batching, traversal routing), as well as policies that have often been considered in academic literature (e.g., savings batching algorithms, largest gap and optimal routing) are tested and evaluated. Due to technological or practical constraints, such as the effects of maverick picking (Glock et al., 2016), warehouses are not able to apply the complex policies provided by academics (Chen et al., 2010). Section 5 returns to this point by providing policy combinations that are able to improve the overall picking performance under different technological and practical constraints.

Besides randomly assigning SKUs to storage locations, four turnover based storage location assignment policies are simulated, in particular across-aisle assignment, within-aisle assignment, diagonal assignment and assigning SKUs across the perimeter of the order picking area. The turnover based policies consists of three product classes: class A stores the fast moving SKUs, class B represents the moderate ordered SKUs and class C stores slow moving SKUs. 
Table 3: Experimental factor setting of the real-life case

\begin{tabular}{lcl}
\hline Factor & \# levels & Factor levels \\
\hline Storage location assignment policy & 5 & Random; within-aisle; across-aisle; diagonal; perimeter \\
Order batching policy & 3 & FCFS; seed; savings \\
Zone picking policy & 5 & Strict; 2 zones (CT); 2 zones (PF); 4 zones (CT); 4 zones $(\mathrm{PF})$ \\
Routing policy & 5 & Aisle-by-aisle; traversal; return; largest gap; optimal \\
\hline
\end{tabular}

$\mathrm{CT}=$ storage zone assignment based on customer type;

$\mathrm{PF}=$ storage zone assignment based on pick frequency.

Within each product class each SKU is randomly assigned to a single storage location. The location of the product classes, as well as the dimension of each class as percent of the total number of storage locations are shown on Figure 2.

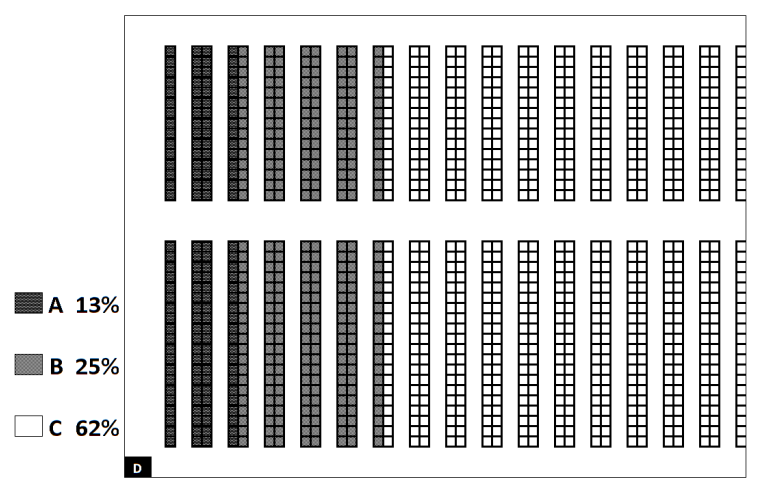

(a) Within-aisle.

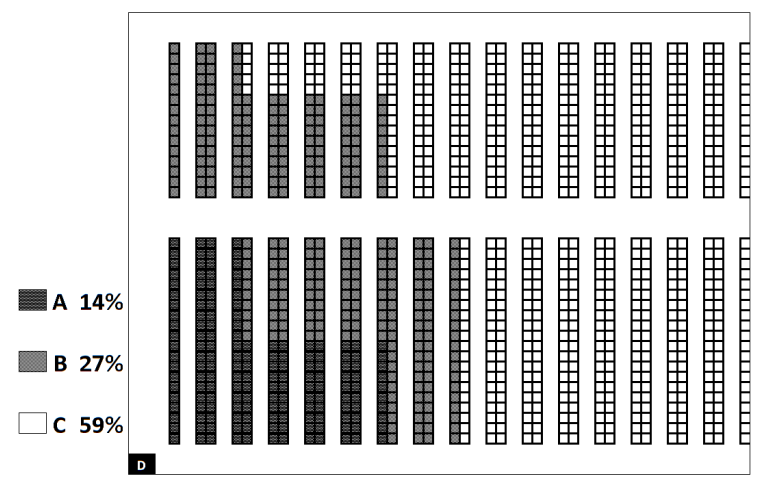

(c) Diagonal.

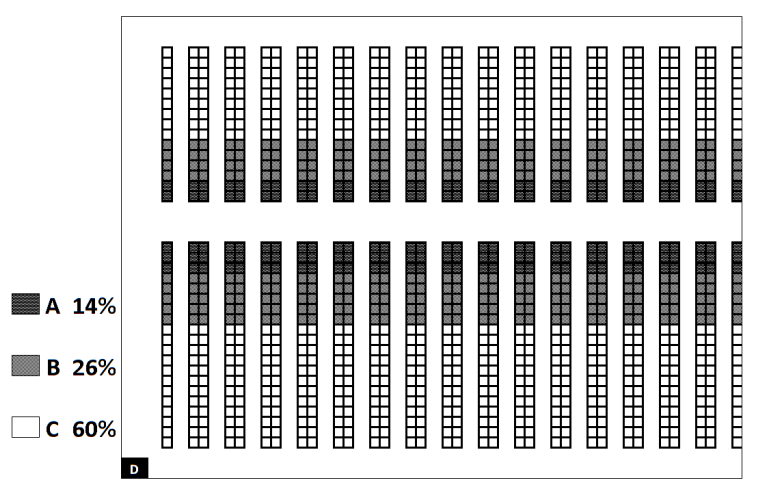

(b) Across-aisle.

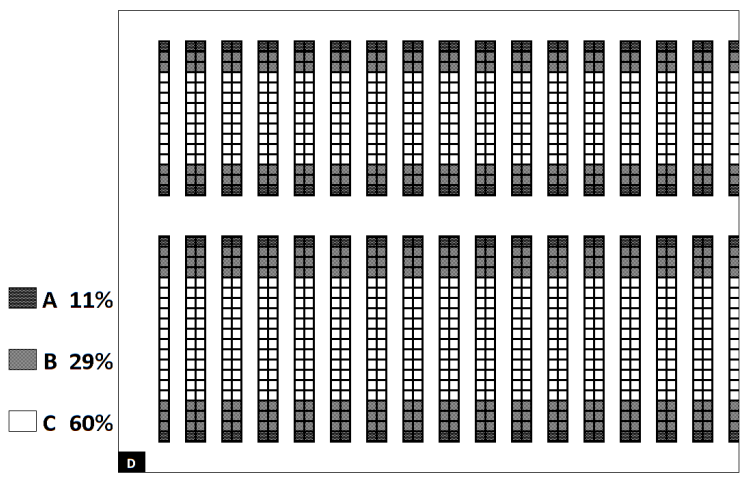

(d) Perimeter.

Figure 2: Location of storage classes.

The currently used FCFS batching policy actually results in a random creation of pick lists in terms of travel distance, as FCFS batching does not take the location of SKUs in the order picking area into account. A seed order batching algorithm is used as an alternative to create batches. The order that requires the smallest number of subaisles to visit, is selected as seed order. Next, the order that minimizes the number of additional subaisles to visit in the 
route is added to the pick list. This algorithm is repeated until the batch contains 26 orders. Subsequently, a new seed order is selected. The cumulative variant of the seed selection rule is simulated, where the number of subaisles that should be visited in a batch is renewed every time an order has been added to a batch. The combination of this seed order selection rule and this accompanying order selection rule has yielded good results for different storage location assignment and routing policies in previous research (De Koster et al., 1999; Ho and Tseng, 2006; Ho et al., 2008). Both FCFS and the seed algorithm are often used in practice because of their simplicity. Additionally, a more sophisticated savings algorithm is tested to compose batches. Savings algorithms are based on the algorithm of Clarke and Wright (1964) for the vehicle routing problem. Pick orders are composed based on the distance saving that can be obtained by combining two or more customer orders into a single pick round. Due to computing time limitations, the basic variant of Clarke-and-Wright (i.e., the savings matrix is calculated only once), denoted by C\&W(i), is analyzed in the simulation experiments. Other Clarke-and-Wright algorithms result in strong increasing computing times and only minor improvements (De Koster et al., 1999).

Strict order picking is compared to four zone picking policies. Both the number of zones as well as the storage zone assignment policy should be determined in case of zone picking. In the simulation experiments, the warehouse is divided into either two or four order picking zones, and SKUs are assigned to order picking zones based on customer type (CT) or pick frequency (PF). This setting results in four additional zone picking policies. The location of the zones is shown on Figure 1. In case the number of zones is equal to two, pick zone $P Z_{1}$ and pick zone $P Z_{2}$ are combined, as well as pick zone $P Z_{3}$ and pick zone $P Z_{4}$. In case multiple zones are combined with a turnover based storage location assignment policy, the location of storage classes in each pick zone is similar to the location of storage classes in a single pick zone as shown on Figure 2.

In addition to the aisle-by-aisle routing heuristic, the travel distance for return, traversal, largest gap, and the optimal route is computed. Examples of the four dedicated routing heuristics are shown on Figure 3. As the routing problem cannot be solved to optimality for a multiple-block warehouse in reasonable computing times, the LinKernighan-Helsgaun (LKH) heuristic for the traveling salesman problem (TSP) is used to approximate the optimal route (Helsgaun, 2000). The LKH heuristic has shown to provide excellent results, both in a general TSP context, and in the context of routing order pickers in a warehouse. Theys et al. (2010) reported an average optimality gap of $0.1 \%$ for different warehouse settings.

To sum up, the simulation experiment consists of 375 possible combinations of policies (i.e., five storage location assignment policies $\times$ three order batching policies $\times$ five zone picking policies $\times$ five routing policies). The factorial setting results in a $5 \times 3 \times 5 \times 5$ full factorial design. To reduce the stochastic effect from order generation, 30 replications per policy combination are performed, resulting in 11,250 observations. During each replication, all combinations of storage, batching, zoning and routing are tested on the same 1,690 randomly generated orders (i.e., 65 pick lists $\times 26$ 


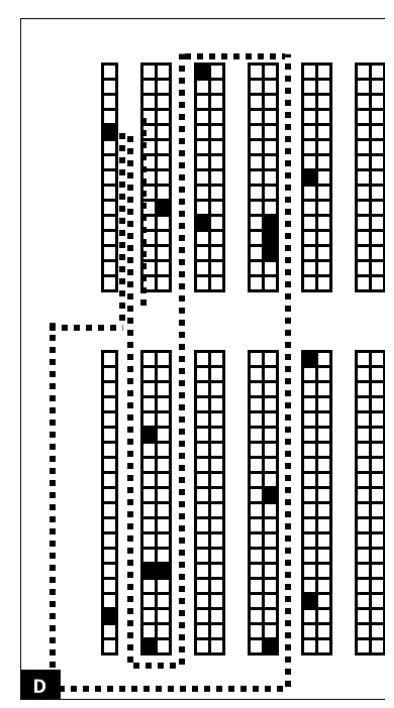

(a) Aisle-by-aisle.

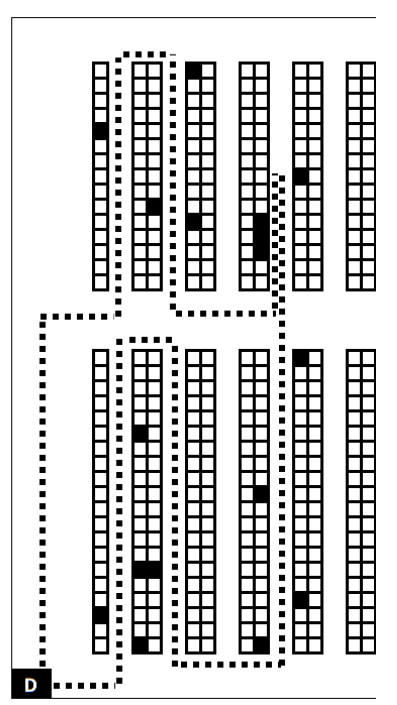

(b) Traversal.

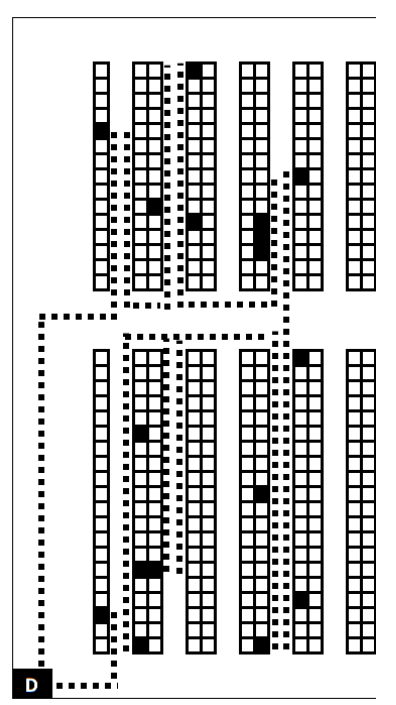

(c) Return.

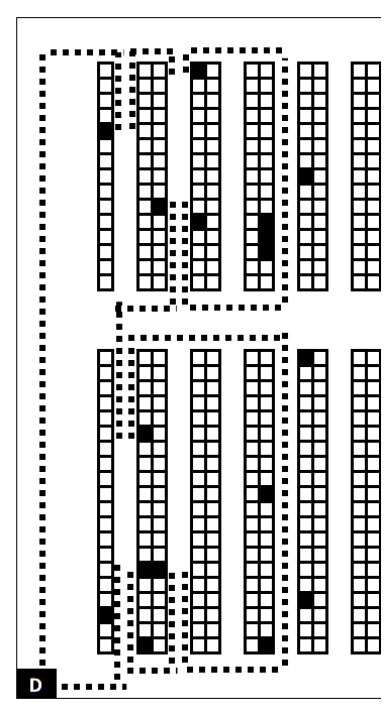

(d) Largest gap.

Figure 3: Dedicated routing heuristics.

orders in each batch). The order size and composition of these 1,690 orders is based on the historical composition of more than 15,000 orders. Order sizes are exponentially distributed with a mean of 2.65 order lines and more frequently ordered SKUs have a higher probability to be generated as order line.

\subsection{Generalized Experimental Design}

In order to validate the conclusions of the case study, the simulation experiment of the real-life warehouse is enlarged to other warehouse settings. As the real-life case study is dedicated to a single warehouse setting, findings should be validated to generalize the conclusions of this study to other warehouse settings. Validation is performed by testing and analyzing the research hypotheses for more generic warehouse designs. In this way, findings and explanations on the relations among order picking planning problems can be used to identify generally well performing policy combinations and formulate general conclusions. Three additional factors that are frequently used in literature to validate new solution methods, will be used to generalize the conclusions of the real-life case: a varying warehouse layout (Petersen, 2002; Theys et al., 2010), a varying order size (De Koster et al., 2012; Petersen, 2002; Theys et al., 2010), and a varying batch capacity (Manzini et al., 2007; Yu and De Koster, 2009). Each of the additional factors consists of three factor levels. Other factors and assumptions formulated in the previous section are similar to the case study.

Compared to the case study (i.e., 16 pick aisles), the warehouse is enlarged to 32 pick aisles and 48 pick aisles. Additionally a more general order picking layout is simulated: the two unequal warehouse blocks are replaced by 
two equal warehouse blocks in correspondence with the traditional warehouse layouts used in academic literature (Roodbergen and De Koster, 2001; Roodbergen, 2012; Shqair et al., 2014; Theys et al., 2010). Furthermore, order sizes are exponentially distributed with a mean of one, three, and five order lines. Finally, the batch capacity factor is set to 10 orders, 25 orders, and 40 orders. Table 4 summarizes the experimental factor setting of the generalized case.

Table 4: Experimental factor setting of the generalized case

\begin{tabular}{lcl}
\hline Factor & \# levels & Factor levels \\
\hline Storage location assignment policy & 5 & Random; within-aisle; across-aisle; diagonal; perimeter \\
Order batching policy & 3 & FCFS; seed; savings \\
Zone picking policy & 5 & Strict; 2 zones $(\mathrm{CT}) ; 2$ zones $(\mathrm{PF}) ; 4$ zones $(\mathrm{CT}) ; 4$ zones $(\mathrm{PF})$ \\
Routing policy & 5 & Aisle-by-aisle; traversal; return; largest gap; optimal \\
Warehouse layout & 3 & 16 aisles; 32 aisles; 48 aisles \\
Order size & 3 & 1 order lines; 3 order lines; 5 order lines \\
Batch capacity & 3 & 10 orders; 25 orders; 40 orders \\
\hline
\end{tabular}

$\mathrm{CT}=$ storage zone assignment based on customer type;

$\mathrm{PF}=$ storage zone assignment based on pick frequency.

To sum up, the simulation experiment of the generalized case consists of 10,125 possible combinations of policies (i.e., five storage location assignment policies $\times$ three order batching policies $\times$ five zone picking policies $\times$ five routing policies $\times$ three warehouse layout levels $\times$ three order size levels $\times$ three batch capacity levels). The factorial setting results in a $5 \times 3 \times 5 \times 5 \times 3 \times 3 \times 3$ full factorial design. The performance of the combination of the four planning problems is evaluated using the same randomly generated order lists for each combination of warehouse layout, order size and batch capacity. By varying the warehouse layout, mean order size, and batch capacity, the results may be easily generalized to other warehouses.

\subsection{Performance Measures}

In order to handle the large number of orders in short time intervals, the efficiency of order picking operations need to be improved. Manual order picking is characterized by the large number of time consuming activities: setup time, search time, pick time, and traveling to, from, and between pick locations. These four time components account for $95 \%$ of the total order pick time (Tompkins et al., 2010). The simulated order picking policies are evaluated with respect to the setup activity, the search activity, as well as traveling of order pickers. Traveling is the most substantial time consuming activity (50\%). Searching and setup account for $20 \%$ and $10 \%$ of the total order pick time, respectively. The time spent on picking items (15\%) at storage locations is assumed to be independent of the applied storage, batching, zoning, and routing policy.

Minimizing total order pick time is a convenient way for evaluating a non-dynamic order pick system in which orders are assumed to be known at the beginning of the planning period (Petersen and Aase, 2004; Quader and Castillo-Villar, 2017). In a dynamic order pick system, order throughput time is more convenient to evaluate performances. As in our case a non-dynamic order pick system is assumed and both performance measures are highly correlated, total order 
pick time is minimized in this study as this mostly results in the smallest order throughput time as well (Giannikas et al., 2017).

The setup activity refers to the time consumed by administrative and setup tasks at the beginning and end of each pick round. The setup time is assumed to be proportional to the number of pick rounds. Searching is defined as the time to identify the storage locations and identification of SKUs. The search time is approximated by evaluating the number of locations that should be visited to retrieve all orders. Finally, the average travel speed in both cross aisles and pick aisles is assumed to be equal. Given a constant travel velocity, minimizing the distance traveled by order pickers is equivalent to minimizing the average travel time of order pickers. Order pickers are assumed to be able to traverse aisles in both directions and to be able to change direction within aisles. Pick aisles are assumed to be wide enough to allow order pickers to pass each other within aisles, preventing wait times as a result of aisle congestion.

\section{Empirical Results}

In order to get a first insight into the results of the simulation experiments, the performance measures of the different factor combinations are analyzed by a full factorial repeated measures ANOVA on average travel distance, average number of pick rounds and average number of visited locations. The assumptions under which the ANOVA $F$ statistic is reliable, are independent observations, homogeneity of variance, as well as normally distributed observations. For each replication, all combinations of storage, batching, routing and zoning are simulated on the same randomly generated orders in order to stress the effects of policy decisions. Consequently, the 11,250 observations are not independent and a repeated measures ANOVA with storage, batching, routing, and zoning as within-subjects factors is required to analyze the main and interaction effects of the planning problems (Cohen et al., 2011). Due to the large number of tested factor combinations, Mauchly's test of homogeneous variances rejected most hypotheses that the variances of the differences between conditions are equal. Since the homogeneity assumption is violated, the $F$-test Type I error rate increases. The Greenhouse-Geisser (G-G) correction of the degrees of freedom is used to compensate for the increased $F$-test type I error rate. The G-G adjustment is the most conservative correction to compensate for the violation of sphericity (Geisser and Greenhouse, 1958; Cohen et al., 2011). In order to ensure the last ANOVA assumption (i.e., normality), the experimental design is balanced. The $F$ statistic is quite robust to violations of normality when group sizes are equal (Cohen et al., 2011).

The results of the ANOVA are presented in the next sections as follows: first, Section 4.1 fulfills the first two research objectives of this study: results of the real-life warehouse simulation are analyzed to test the research hypotheses and to explain why and how the individual planning problems of storage, batching, zoning and routing are related. The conclusions of the real-life case study are validated and generalized to other warehouses by analyzing the simulation 
results of the generalized case in Section 4.2.

Table 5: $5 \times 3 \times 5 \times 5$ full factorial repeated measures ANOVA on average travel distance

\begin{tabular}{|c|c|c|c|c|c|}
\hline & Sum of squares & $\mathrm{df}$ & Mean square & $F$ & $p$-value \\
\hline \multicolumn{6}{|l|}{ Main effects } \\
\hline $\begin{array}{l}\text { Storage } \\
\text { Batching } \\
\text { Zoning } \\
\text { Routing }\end{array}$ & $\begin{array}{r}28,565,916,920 \\
421,484,570,256 \\
303,589,976,898 \\
52,259,090,330\end{array}$ & $\begin{array}{l}3.00 \\
1.81 \\
2.40 \\
3.14\end{array}$ & $\begin{array}{r}9,528,113,270 \\
232,630,801,415 \\
126,491,824,693 \\
14,663,524,503\end{array}$ & $\begin{array}{r}19,512.62 \\
502,015.57 \\
51,642.26 \\
94,142.19\end{array}$ & $\begin{array}{l}0.000 \\
0.000 \\
0.000 \\
0.000\end{array}$ \\
\hline \multicolumn{6}{|l|}{ Two-way interaction } \\
\hline $\begin{array}{l}\text { Storage } \times \text { batching } \\
\text { Storage } \times \text { zoning } \\
\text { Storage } \times \text { routing } \\
\text { Batching } \times \text { zoning } \\
\text { Batching } \times \text { routing } \\
\text { Zoning } \times \text { routing }\end{array}$ & $\begin{array}{r}2,115,987,384 \\
17,292,769,630 \\
9,970,923,340 \\
50,034,223,170 \\
6,756,931,911 \\
7,651,407,057\end{array}$ & $\begin{array}{l}6.16 \\
7.76 \\
6.92 \\
5.25 \\
3.27 \\
4.14\end{array}$ & $\begin{array}{r}343,569,720 \\
2,228,256,294 \\
1,440,588,668 \\
9,529,532,547 \\
2,065,561,184 \\
1,848,894,174\end{array}$ & $\begin{array}{r}2,357.78 \\
3,812.92 \\
8,359.33 \\
23,747.10 \\
13,980.56 \\
5,230.31\end{array}$ & $\begin{array}{l}0.000 \\
0.000 \\
0.000 \\
0.000 \\
0.000 \\
0.000\end{array}$ \\
\hline \multicolumn{6}{|l|}{ Residuals } \\
\hline $\begin{array}{l}\text { Between subjects } \\
\text { Within storage } \\
\text { Within batching } \\
\text { Within zoning } \\
\text { Within routing } \\
\text { Within storage } \times \text { batching } \\
\text { Within storage } \times \text { zoning } \\
\text { Within storage } \times \text { routing } \\
\text { Within batching } \times \text { zoning } \\
\text { Within batching } \times \text { routing } \\
\text { Within zoning } \times \text { routing }\end{array}$ & $\begin{array}{r}1,652,597 \\
42,455,169 \\
24,347,955 \\
146,767,923 \\
16,098,134 \\
26,026,054 \\
137,355,065 \\
34,590,906 \\
61,101,886 \\
14,015,963 \\
42,424,016\end{array}$ & $\begin{array}{r}29.00 \\
86.94 \\
52.54 \\
72.54 \\
91.03 \\
178.61 \\
219.48 \\
200.72 \\
152.26 \\
94.87 \\
120.01\end{array}$ & $\begin{array}{r}56,986 \\
488,305 \\
463,394 \\
2,023,312 \\
176,850 \\
145,718 \\
625,831 \\
172,333 \\
401,293 \\
147,745 \\
353,496\end{array}$ & & \\
\hline Total & $900,342,164,257$ & $1,338.72$ & & & \\
\hline
\end{tabular}

Table 6: $5 \times 3 \times 5 \times 5$ full factorial repeated measures ANOVA on average number of pick rounds

\begin{tabular}{|c|c|c|c|c|c|}
\hline & Sum of squares & $\mathrm{df}$ & Mean square & $F$ & $p$-value \\
\hline \multicolumn{6}{|l|}{ Main effects } \\
\hline $\begin{array}{l}\text { Storage } \\
\text { Batching } \\
\text { Zoning } \\
\text { Routing }\end{array}$ & $\begin{array}{r}2.51 \\
28.87 \\
1,367,788.93 \\
6.7\end{array}$ & $\begin{array}{l}3.40 \\
1.00 \\
2.56 \\
2.96\end{array}$ & $\begin{array}{r}0.74 \\
28.87 \\
533,355.21 \\
2.26\end{array}$ & $\begin{array}{r}26.95 \\
201.96 \\
13,804.38 \\
53.87\end{array}$ & $\begin{array}{l}0.000 \\
0.000 \\
0.000 \\
0.000\end{array}$ \\
\hline \multicolumn{6}{|l|}{ Two-way interaction } \\
\hline $\begin{array}{l}\text { Storage } \times \text { batching } \\
\text { Storage } \times \text { zoning } \\
\text { Storage } \times \text { routing } \\
\text { Batching } \times \text { zoning } \\
\text { Batching } \times \text { routing } \\
\text { Zoning } \times \text { routing }\end{array}$ & $\begin{array}{r}5.02 \\
1.85 \\
5.77 \\
14.26 \\
13.40 \\
7.05\end{array}$ & $\begin{array}{l}3.40 \\
8.70 \\
7.84 \\
2.14 \\
2.96 \\
5.90\end{array}$ & $\begin{array}{l}1.47 \\
0.21 \\
0.74 \\
6.65 \\
4.53 \\
1.19\end{array}$ & $\begin{array}{r}26.95 \\
4.64 \\
14.26 \\
21.48 \\
53.87 \\
13.72\end{array}$ & $\begin{array}{l}0.000 \\
0.000 \\
0.000 \\
0.000 \\
0.000 \\
0.000\end{array}$ \\
\hline \multicolumn{6}{|l|}{ Residuals } \\
\hline $\begin{array}{l}\text { Between subjects } \\
\text { Within storage } \\
\text { Within batching } \\
\text { Within zoning } \\
\text { Within routing } \\
\text { Within storage } \times \text { batching } \\
\text { Within storage } \times \text { zoning } \\
\text { Within storage } \times \text { routing } \\
\text { Within batching } \times \text { zoning } \\
\text { Within batching } \times \text { routing } \\
\text { Within zoning } \times \text { routing }\end{array}$ & $\begin{array}{r}2,305 \\
2.70 \\
4.15 \\
2,873.43 \\
3.61 \\
5.40 \\
11.60 \\
11.74 \\
19.25 \\
7.21 \\
14.91\end{array}$ & $\begin{array}{r}29.00 \\
98.70 \\
29.00 \\
74.37 \\
85.83 \\
98.70 \\
252.33 \\
227.34 \\
62.16 \\
85.83 \\
171.19\end{array}$ & $\begin{array}{r}0.08 \\
0.03 \\
0.14 \\
38.64 \\
0.04 \\
0.05 \\
0.05 \\
0.05 \\
0.31 \\
0.08 \\
0.09\end{array}$ & & \\
\hline Total & $1,373,133.36$ & $1,255.32$ & & & \\
\hline
\end{tabular}


Table 7: $5 \times 3 \times 5 \times 5$ full factorial repeated measures ANOVA on average number of visited locations

\begin{tabular}{|c|c|c|c|c|c|}
\hline & Sum of squares & $\mathrm{df}$ & Mean square & $F$ & $p$-value \\
\hline \multicolumn{6}{|l|}{ Main effects } \\
\hline $\begin{array}{l}\text { Storage } \\
\text { Batching } \\
\text { Zoning } \\
\text { Routing }\end{array}$ & $\begin{array}{r}19,857,165 \\
1,606,293,435 \\
538,617,997 \\
2,556,886\end{array}$ & $\begin{array}{l}3.44 \\
1.21 \\
2.82 \\
3.22\end{array}$ & $\begin{array}{r}5,774,199 \\
1,322,451,977 \\
190,785,132 \\
794,644\end{array}$ & $\begin{array}{r}2,801.40 \\
50,892.63 \\
14,516.94 \\
4,689.53\end{array}$ & $\begin{array}{l}0.000 \\
0.000 \\
0.000 \\
0.000\end{array}$ \\
\hline \multicolumn{6}{|l|}{ Two-way interaction } \\
\hline $\begin{array}{l}\text { Storage } \times \text { batching } \\
\text { Storage } \times \text { zoning } \\
\text { Storage } \times \text { routing } \\
\text { Batching } \times \text { zoning } \\
\text { Batching } \times \text { routing } \\
\text { Zoning } \times \text { routing }\end{array}$ & $\begin{array}{r}16,008,512 \\
3,731,458 \\
140,542 \\
68,883,249 \\
5,113,772 \\
446,489\end{array}$ & $\begin{array}{r}5.31 \\
9.12 \\
10.08 \\
4.69 \\
3.22 \\
9.96\end{array}$ & $\begin{array}{r}3,013,365 \\
409,260 \\
13,945 \\
14,672,337 \\
1,589,288 \\
44,835\end{array}$ & $\begin{array}{r}1,803.96 \\
121.47 \\
57.63 \\
2,622.27 \\
4,689.53 \\
202.84\end{array}$ & $\begin{array}{l}0.000 \\
0.000 \\
0.000 \\
0.000 \\
0.000 \\
0.000\end{array}$ \\
\hline \multicolumn{6}{|l|}{ Residuals } \\
\hline $\begin{array}{l}\text { Between subjects } \\
\text { Within storage } \\
\text { Within batching } \\
\text { Within zoning } \\
\text { Within routing } \\
\text { Within storage } \times \text { batching } \\
\text { Within storage } \times \text { zoning } \\
\text { Within storage } \times \text { routing } \\
\text { Within batching } \times \text { zoning } \\
\text { Within batching } \times \text { routing } \\
\text { Within zoning } \times \text { routing }\end{array}$ & $\begin{array}{r}80,942 \\
205,561 \\
915,309 \\
1,075,979 \\
15,812 \\
257,349 \\
890,827 \\
70,719 \\
761,788 \\
31,624 \\
63,836\end{array}$ & $\begin{array}{r}29.00 \\
99.73 \\
35.22 \\
74.10 \\
93.31 \\
154.06 \\
264.41 \\
292.27 \\
136.15 \\
93.31 \\
288.79\end{array}$ & $\begin{array}{r}2,791 \\
2,061 \\
25.985 \\
14,520 \\
169 \\
1,670 \\
3,369 \\
242 \\
5,595 \\
339 \\
221\end{array}$ & & \\
\hline Total & $2,266,019,250$ & $1,613.17$ & & & \\
\hline
\end{tabular}

\subsection{Results of Real-life Case Study}

In the simulation experiments of the real-life warehouse, a balanced $5 \times 3 \times 5 \times 5$ full factorial repeated measures ANOVA, with storage, batching, zoning, and routing as the within-subjects factors, is used to prove the value of combining the four order picking planning problems. The results of the repeated measures ANOVA on average travel distance, number of pick rounds, and number of visited locations are shown in Tables 5, 6, and 7, respectively. The first three columns show the sum of squares, the G-G degrees of freedom and the resulting mean square for the main and interactions effects, as well as for the residuals. The last two columns are devoted to the $F$ statistic and the $p$-value for testing the statistical significance of storage, batching, zoning, and routing, as well as the interactions among the four operational planning problems.

Tables 5,6, and 7 indicate that the main effects of storage location assignment, order batching, zoning and routing are statistically significant with respect to the three performance measures. This means that there is a significant difference between the five storage location policies, the three order batching policies, the five zoning policies, as well as the five different routing policies on the average distance traveled by order pickers, the average number of pick rounds, and the number of visited storage locations. The decision on which storage, which batching, which zoning, and which routing policy to use does influence the order picking performance.

Furthermore, Tables 5, 6, and 7 show that all factors in the simulation experiment are significantly interacting with 
each other with respect to each of the three performance measures. As three out of the four factors in the experiment contain five levels, the 30 replications give rise to a large number of observations. Null hypotheses are much easier rejected with a large number of factor levels and a large number of observations because of a greater probability that one of the factor levels is interacting with another factor level (Field, 2013). However, the ANOVA shows strong statistically significant effects, at least with respect to the travel distance, and for some interactions regarding the number of visited locations (e.g., storage-batching, batching-zoning, and batching-routing).

The next six sections (Sections 4.1.1, 4.1.2, 4.1.3, 4.1.4, 4.1.5, and 4.1.6) are devoted to explaining and discussing why planning problems are related. As ANOVA results show that interaction terms are most strong in terms of travel distance and traveling is the most time consuming activity, each combination of planning problems is discussed with respect to the distance traveled by order pickers. As differences in number of pick rounds are too small to be relevant in practice, this performance measure does not contribute to the discussion on why planning problems are related. For example, the maximum difference in number of pick rounds between the combinations of storage and batching policies is only 0.16 pick rounds. Consequently, the number of pick rounds is not discussed throughout the next sections. The performance measure 'number of visited locations' is discussed only for combinations that show substantial differences (i.e., storage-batching, batching-zoning, and batching-routing).

\subsubsection{Storage Location Assignment and Order Batching}

The first hypothesis states that the joint effect of storage location assignment and order batching significantly impacts order picking performance (Hypothesis 1). The ANOVA results of Tables 5, 6 and 7 support the hypothesis of the relation between storage and batching. The two-way interaction of storage and batching is statistically significant with respect to the distance traveled, the number of pick rounds, and the number of visited locations. However, differences in number of pick rounds are too small to be relevant in practice.

Table 8: Post hoc multiple t-test for storage policies by batching policies using Dunnett's method (familywise error rate $=0.01)$

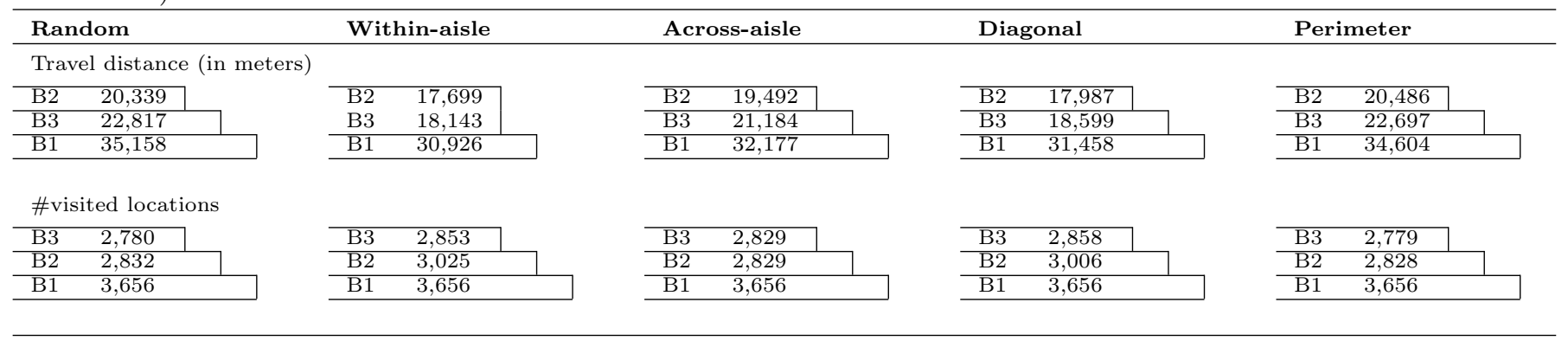

$\mathrm{B} 1=\mathrm{FCFS} ; \mathrm{B} 2=$ seed $; \mathrm{B} 3=$ savings

In order to analyze why the relation between storage and batching planning problems is important, the statistical 


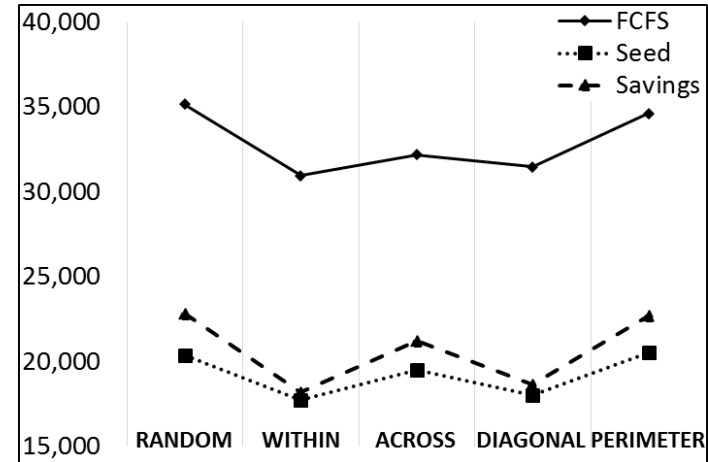

(a)

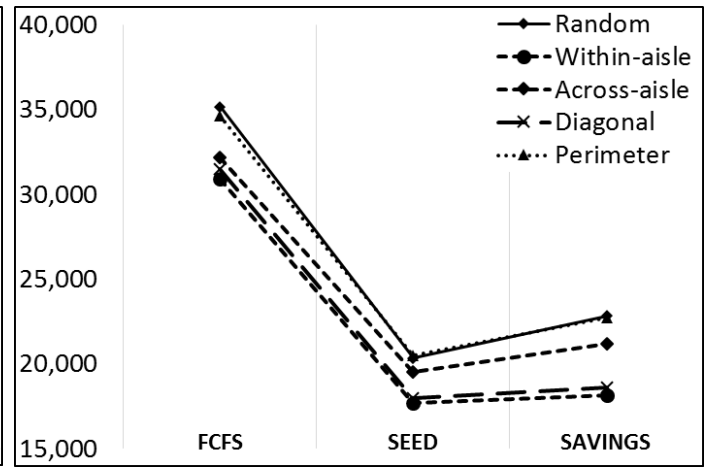

(b)

Figure 4: Average travel distance (in meters) for each combination of storage and batching policy.

significance of all levels of the batching factor is analyzed for each storage factor level using Dunnett's method. Table 8 summarizes the test results of a post hoc test. Dunnett's pairwise test procedure is a robust technique in terms of power and control of the Type I error rate for evaluating multiple hypotheses in case of unequal variances (Field, 2013). If two order picking policies are listed in the same subset in Table 8, differences fail to be statistically significant. Minor differences exists in the composition of subsets between different storage location assignment policies. In terms of travel distance, all batching policies are located in a separate subset except for the combination with within-aisle storage classes. Results of the post hoc tests indicate that the route length difference between the seed and savings batching policies is not statistically significant in combination with within-aisle storage classes, while in combination with other storage policies, the seed batching outperforms other batching policies. FCFS batching is situated in the last subset for each storage assignment policy.

No differences in the composition of subsets can be observed with respect to the number of visited locations. However, the seed algorithm shows strong differences among storage location assignment policies. A decreased number of visited locations can be observed in combination with random, across-aisle and perimeter storage classes. This can be explained as follows: fast moving items are located in all pick aisles in case of random, across-aisle and perimeter storage and the considered seed batching policy minimizes the number of aisles to visit. Consequently, if a particular aisle should be visited in a pick tour, the limited number of A-locations in the aisle are most likely to be visited, while aisles of within-aisle and diagonal storage classes consist of a large number of A-locations with equal probability of being visited.

The interaction plots of Figure 4 further illustrate why storage location assignment and order batching are related with respect to travel distance. The savings algorithm shows strong performance improvements in combination with within-aisle and diagonal storage location assignment policies, compared to the other storage policies. The savings algorithm is able to approximate the average travel distance of the cumulative seed batching algorithm in case of 
within-aisle or diagonal storage classes. These storage policies locate classes over the entire subaisle and storage locations within each subaisle have an equal probability of being visited. As seed batching only aims to minimize the number of visited subaisles in a pick round and the savings algorithm additionally takes the travel distance within a pick aisle into account while creating batches, the efficiency benefits resulting from within-aisle and diagonal storage are much larger in combination with savings batching. In case the number of A-locations is small in each subaisle, seed batching results in shorter route lengths.

\subsubsection{Storage Location Assignment and Picker Routing}

Simulation results support the second hypothesis (Hypothesis 2): Tables 5, 6 and 7 show that storage location assignment and order picker routing are statistically significantly related with respect to the travel distance, the number of pick rounds, and the number of visited locations. Differences in number of pick rounds and number of visited locations are negligible small.

Table 9: Post hoc multiple t-test for storage policies by routing policies using Dunnett's method (familywise error rate $=0.01)$

\begin{tabular}{|c|c|c|c|c|c|c|c|c|c|}
\hline \multicolumn{2}{|c|}{ Random } & \multicolumn{2}{|c|}{ Within-aisle } & \multicolumn{2}{|c|}{ Across-aisle } & \multicolumn{2}{|c|}{ Diagonal } & \multicolumn{2}{|c|}{ Perimeter } \\
\hline \multicolumn{10}{|c|}{ Travel distance (in meters) } \\
\hline $\mathrm{R} 5$ & 22,360 & $\mathrm{R} 5$ & 18,882 & R5 & 20,193 & R5 & 19,293 & $\mathrm{R} 5$ & 21,004 \\
\hline $\mathrm{R} 2$ & 25,441 & $\mathrm{R} 2$ & 21,977 & R3 & 23,066 & $\mathrm{R} 2$ & 22,470 & $\mathrm{R} 4$ & 24,340 \\
\hline R4 & $\begin{array}{l}20,441 \\
26,825\end{array}$ & $\mathrm{R} 4$ & 22,823 & R4 & 24,412 & R4 & 23,305 & R2 & $\begin{array}{l}24,040 \\
25,899\end{array}$ \\
\hline R3 & $\begin{array}{l}27,693 \\
27,620\end{array}$ & R3 & 23,207 & $\mathrm{R} 2$ & $\begin{array}{l}24,+12 \\
25,770\end{array}$ & R3 & 23,779 & $\mathrm{R} 1$ & 28,899 \\
\hline $\mathrm{R} 1$ & 28,204 & $\mathrm{R} 1$ & 24,392 & $\mathrm{R} 1$ & 27,981 & $\mathrm{R} 1$ & 24,559 & R3 & 29,503 \\
\hline
\end{tabular}

\footnotetext{
$\mathrm{R} 1=$ aisle-by-aisle; $\mathrm{R} 2=$ traversal; $\mathrm{R} 3=$ return; $\mathrm{R} 4=$ largest gap; $\mathrm{R} 5=$ optimal
}

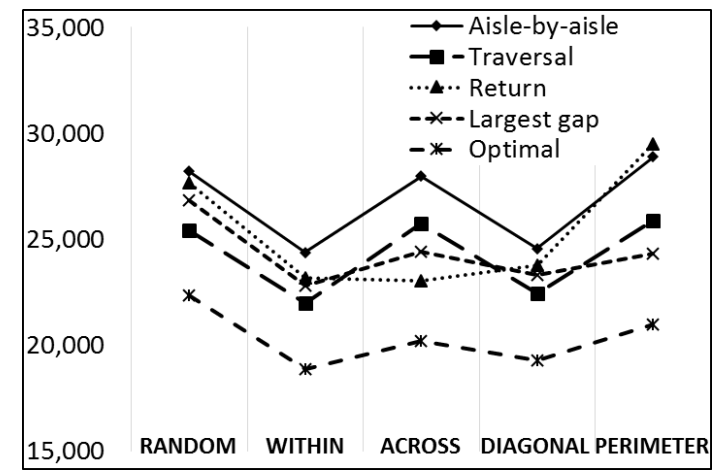

(a)

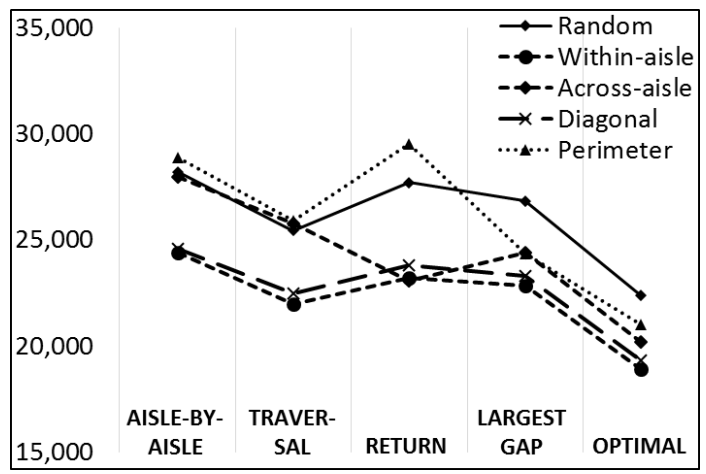

(b)

Figure 5: Average travel distance in meter for each combination of storage and routing policy.

The statistical significance of all levels of the storage factor, decomposed in routing policies, is analyzed using Dunnett's method for pairwise comparisons in order to explain why both planning problems are related. Table 9 presents the results of the post hoc test. The strong statistically significant interaction between storage and routing 
planning problems gives rise to the creation of varying subsets for each storage location assignment policy. Over all storage levels, the optimal routing policy outperforms the other routing policies that are often used in practice with respect to the average travel distance. The composition of the other subsets strongly differs across the different storage location assignment policies.

When randomly assigning SKUs to storage locations, only minor differences exist in the performance of the dedicated routing heuristics. All pick aisles and all storage locations have an equal probability of being visited in a pick tour. In other words, as pick densities are equally distributed across aisles as well as within each pick aisle, random storage does not clearly favor any of the dedicated routing heuristics. No clear subsets of routing policies in combination with random storage have been formed by the post hoc test.

Including information about the location of fast moving products while composing order picker routes favors certain routing heuristics. From Figure 5, the combination of perimeter storage policy and largest gap routing policy is an example of a well performing combination. Since fast moving SKUs are stored along the periphery of the warehouse blocks and the largest gap routes tend to follow the periphery of the warehouse, this policy combination outperforms aisle-by-aisle and return routing in combination with perimeter storage location assignment. Other routing policies show a strong increase in travel distance in combination with the perimeter storage compared to other storage location assignment policies. Furthermore, return routes are preferred in combination with across-aisle storage classes: return routes aim to reduce the travel distance within aisles and across-aisle storage location assignment increases pick densities in the front of each pick aisle. Equivalent to the perimeter-largest gap combination, routing methods show increasing route lengths in combination with across-aisle storage, except for return routing. Finally, the traversal routing is preferred in combination with within-aisle and diagonal storage classes as the aim is to increase the pick density within an aisle (i.e., within-aisle and diagonal) and reduce the number of visiting aisles in a pick tour (i.e., traversal). However, this difference is not found to be statistically significant by the post hoc tests.

In summary, the statistically significant interaction between storage location assignment and order picker routing originates from the fact that some combinations of storage and routing policies yield excellent performances, while other combinations result in large average travel distances. Fast moving items should be assigned to storage locations that could be accessed most easily, which strongly depends on the routing policy.

\subsubsection{Order Batching and Picker Routing}

Hypothesis 3 states that a significant interaction exists between the batching and routing planning problems. The two-way interaction between order batching and picker routing is found to be statistically significant with respect to all three performance measures. ANOVA results approve Hypothesis 3: the efficiency of order batching is significantly influenced by the applied routing method. With respect to the number of pick rounds, differences between policy 
combinations of batching and routing are too small to discuss them meaningfully.

In order to analyze why the batching and routing planning problems are related, the simulation results are analyzed using Dunnett's post hoc test (see Table 10). Additionally, the results are illustrated on the interaction plots of Figure 6.

Table 10: Post hoc multiple t-test for batching policies by routing policies using Dunnett's method (familywise error rate $=0.01)$

\begin{tabular}{|c|c|c|c|c|c|}
\hline \multicolumn{2}{|c|}{ FCFS } & \multicolumn{2}{|c|}{ Seed } & \multicolumn{2}{|c|}{ Savings } \\
\hline \multicolumn{6}{|c|}{ Travel distance (in meters) } \\
\hline & 27,406 & $\mathrm{R} 5$ & 16,423 & R5 & 17,211 \\
\hline R4 & 32,450 & $\mathrm{R} 2$ & 18,924 & R4 & 20,885 \\
\hline $\mathrm{R} 2$ & 32,734 & R3 & 19,471 & $\mathrm{R} 2$ & 21,278 \\
\hline R3 & 35,549 & $\mathrm{R} 4$ & 19,689 & R3 & 21,328 \\
\hline $\mathrm{R} 1$ & 36,184 & $\mathrm{R} 1$ & 21,497 & $\mathrm{R} 1$ & 22,740 \\
\hline \multicolumn{6}{|c|}{ \#visited locations } \\
\hline $\mathrm{R} 1$ & 3,656 & R1 & 2,904 & R3 & 2,749 \\
\hline $\mathrm{R} 2$ & 3,656 & $\mathrm{R} 2$ & 2,904 & R5 & 2,781 \\
\hline R3 & 3,656 & R3 & 2,904 & $\mathrm{R} 4$ & 2,826 \\
\hline $\mathrm{R} 4$ & 3,656 & $\mathrm{R} 4$ & 2,904 & $\mathrm{R} 2$ & 2,826 \\
\hline R5 & 3,656 & R5 & 2,904 & R1 & 2,882 \\
\hline
\end{tabular}

$\mathrm{R} 1=$ aisle-by-aisle; $\mathrm{R} 2=$ traversal; $\mathrm{R} 3=$ return; $\mathrm{R} 4=$ largest gap; $\mathrm{R} 5=$ optimal

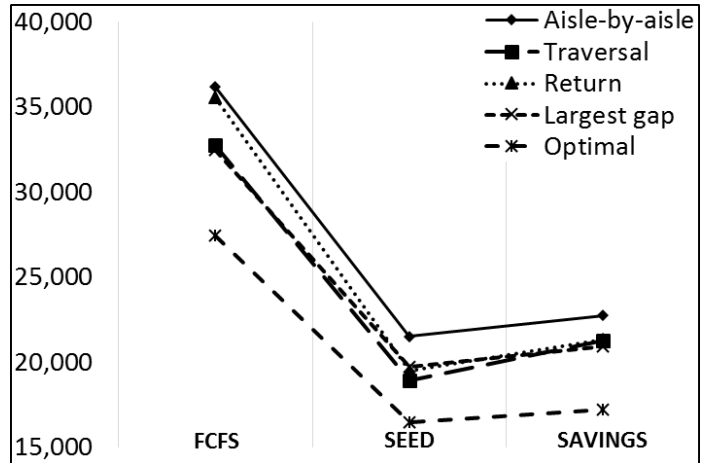

(a)

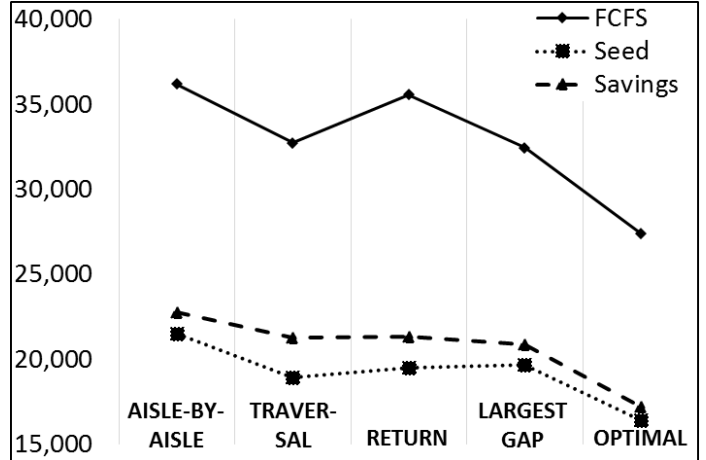

(b)

Figure 6: Average travel distance in meter for each combination of batching and routing policy.

Combinations of more straightforward routing policies (i.e., aisle-by-aisle and return) with FCFS batching appear to be inefficient in terms of travel distance (see Figure 6). The post hoc test shows that aisle-by-aisle and return routing form the last subset in combination with FCFS batching. FCFS batching, which in fact results in a random creation of batches, generates pick lists with SKUs located in a large number of aisles and SKUs are diffused within each aisle. Aisle-by-aisle routes can work efficiently only if the number of aisles to be visited is minimized, while return routes aim to minimize the travel distance within a pick aisle. This results in a large travel distance when combining FCFS batching with either the aisle-by-aisle or return routing policy. The average route length difference between FCFS batching and seed or savings batching is much larger when combined with aisle-by-aisle and return routing compared 
to other routing policies. Moreover, the efficiency of the return routing policy strongly increases in combination with the seed batching policy and the savings batching policy. Especially, when integrating the routing policy while creating batches (i.e., savings batching), the importance of the decision which routing policy to use substantially reduces. As the savings algorithm is based on the travel distance reduction of combining orders, the route length of combinations of orders, depending on the applied routing policy, is calculated before batches are composed. As a result traversal, return and largest gap routing policies form a single subset in case of savings batching.

Minor differences exist in the number of visited locations between the combinations of batching and routing (see Table 10). In case of FCFS batching and seed batching, the number of visited locations is insensitive to the routing policy. As the savings algorithm takes the routing policy into account while calculating the savings between combinations of orders, the composition of batches differ between the routing policies. Consequently, the number of visited locations varies for different routing policies in combination with the savings batching policy. However, the statistically significant differences between the routing policies are rather small: the number of visited locations vary only $4.8 \%$ in case of savings batching.

\subsubsection{Storage Location Assignment and Zone Picking}

The order picking system performance is expected to be significantly influenced by the combined effect of storage location assignment and zone picking. Table 5 shows that the two-way interaction is statistically significant with respect to the travel distance of order pickers. In the context of the two other performance measures, the joint effect of storage location assignment and zone picking on order picking performance is statistically significant as well. So, Hypothesis 4 is supported by the ANOVA results. However, variations are practically irrelevant with respect to the number of pick rounds and the number of visited locations. This subsection focuses on explaining why the interaction between storage location assignment and zone picking is statistically significant with respect to the travel distance.

Table 11: Post hoc multiple t-test for zoning policies by storage policies using Dunnett's method (familywise error rate $=0.01)$

\begin{tabular}{|c|c|c|c|c|}
\hline Strict & 2 zones (CT) & 2 zones (PF) & 4 zones (CT) & 4 zones $(\mathrm{PF})$ \\
\hline \multicolumn{5}{|c|}{ Travel distance (in meters) } \\
\hline 27,942 & 21,273 & 25,419 & 16,212 & 20,436 \\
\hline 29,096 & 21,758 & 25,647 & 16,398 & 20,508 \\
\hline 33,140 & 23,696 & 26,242 & 17,449 & 20,895 \\
\hline 36,534 & 25,853 & 27,018 & 18,601 & 21,326 \\
\hline 37,471 & 26,107 & 27,019 & 18,722 & 21,517 \\
\hline
\end{tabular}

$\mathrm{S} 1=$ random $; \mathrm{S} 2=$ within-aisle; $\mathrm{S} 3=$ across-aisle; $\mathrm{S} 4=$ diagonal; $\mathrm{S} 5=$ perimeter

Results of the post hoc tests, shown in Table 11, explain why storage location assignment and zone picking are strongly related. In case of assigning SKUs to order picking zones based on the pick frequency, the applied storage 


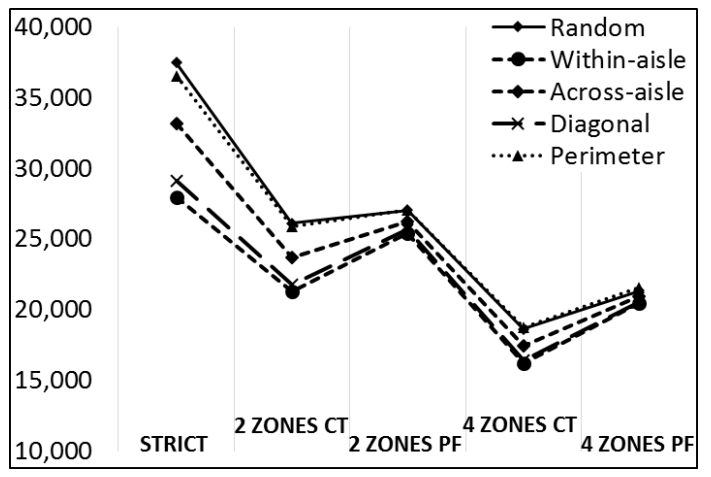

(a)

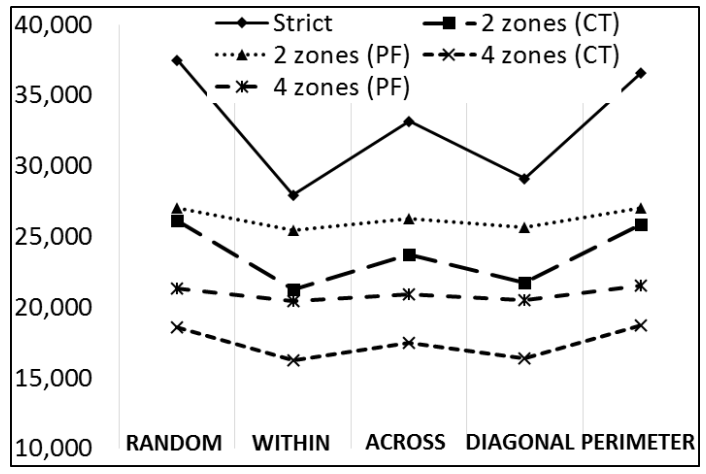

(b)

Figure 7: Average travel distance in meter for each combination of storage and zoning policy.

location assignment policy seems to be irrelevant. A single subset containing all storage policies is created in case of pick frequency assignment of SKUs to order picking zones, indicating that the travel distance is not statistically significantly different for each of the five storage policies. Products assigned to each order picking zone are characterized by a similar demand. If demand is distributed uniformly, turnover based storage location assignment policies are not able to reduce order picker traveling compared to randomly assigning products to storage locations. This effect is illustrated on Figure 7(b) by the rather flat line for 2 zones (PF) and 4 zones (PF).

The strict order picking policy, as well as the customer type assignment of SKUs to zones (2 zones (CT) and 4 zones $(\mathrm{CT})$ ) result in the same composition of subsets. Within-aisle storage and diagonal storage outperform other storage assignment policies with respect to travel distance. The example shown on Figure 7 further illustrates why the statistically significant interaction exists: the effect of different storage location assignment policies is not consistent over all levels of zoning. By dividing the warehouse into order picking zones, the effect of shifting to a more efficient storage policy on the route length is reduced compared to the strict order picking policy. The reason for this significant interaction term can be found in the smaller area that is crossed by order pickers to retrieve all items on the pick list in case of two or four order picking zones, as well as in case of turnover based storage location assignment. Zoning policies as well as storage policies aim to increase the density of SKUs retrieved in each aisle. Consequently, the performance impact resulting from changing the storage policy is far greater in combination with strict order picking, compared to other zone picking policies. Thus, decreasing the zone size by increasing the number of zones diminishes the efficiency benefits resulting from turnover based storage as order pickers are limited to a small pick area. Dividing the order picking area into more than four zones may adversely affect the order picking efficiency in the case study. If the number of zones exceeds the number of customer types, sorting operations increase and more order picking routes are composed. Order pickers are operating at less than full capacity, especially for unpopular zones. Since orders should be picked before due dates, pick lists are released before the capacity has been reached. 


\subsubsection{Order Batching and Zone Picking}

ANOVA results of Tables 5, 6 and 7 support Hypothesis 5 that order batching and zone picking planning problems are strongly related. The joint effect on the number of pick rounds is not discussed due to the lack of practical significance of the observed differences between the policy combinations. Especially with respect to the distance traveled by order pickers to retrieve all items, Table 5 shows a strong two-way interaction between order batching and zone picking.

Table 12: Post hoc multiple t-test for zoning policies by batching policies using Dunnett's method (familywise error rate $=0.01)$

\begin{tabular}{|c|c|c|c|c|c|c|c|c|c|}
\hline \multicolumn{2}{|c|}{ Strict } & \multicolumn{2}{|c|}{2 zones $(\mathrm{CT})$} & \multicolumn{2}{|c|}{2 zones (PF) } & \multicolumn{2}{|c|}{4 zones $(\mathrm{CT})$} & \multicolumn{2}{|c|}{4 zones $(\mathrm{PF})$} \\
\hline \multicolumn{10}{|c|}{ Travel distance (in meters) } \\
\hline $\mathrm{B} 2$ & 25,261 & $\mathrm{~B} 2$ & 19,132 & B2 & 19,771 & $\mathrm{~B} 2$ & 15,198 & $\mathrm{~B} 2$ & 16,641 \\
\hline B3 & 27,700 & B3 & 20,768 & B3 & 22,118 & B3 & 15,723 & B3 & 17,132 \\
\hline B1 & 45,549 & B1 & 31,312 & B1 & 36,918 & B1 & 21,508 & $\mathrm{~B} 1$ & 29,036 \\
\hline \multicolumn{10}{|c|}{ \#visited locations } \\
\hline B3 & 3,077 & B3 & 2,876 & B3 & 2,952 & B3 & 2,514 & B3 & 2,645 \\
\hline $\mathrm{B} 2$ & 3,135 & $\mathrm{~B} 2$ & 2,906 & $\mathrm{~B} 2$ & 3,028 & $\mathrm{~B} 2$ & 2,553 & $\mathrm{~B} 2$ & 2,897 \\
\hline B1 & 3,893 & B1 & 3,592 & B1 & 3,868 & B1 & 3,126 & B1 & 3,801 \\
\hline
\end{tabular}

$\mathrm{B} 1=\mathrm{FCFS} ; \mathrm{B} 2=$ seed; $\mathrm{B} 3=$ savings

The post hoc test, shown in Table 12, creates three identical subsets for each zone picking policy. All five zone picking policies result in the same composition of subsets. The three batching policies result in statistically significantly different performances, both in terms of travel distance and in number of visited locations. The seed batching policy yields the shortest routes, while the C\&W(i) savings algorithm scores better on 'number of visited locations' by combining more orders that should visit identical storage locations on the created pick lists. Differences between the seed and savings batching policy with respect to the number of visited locations are minor in practice, except for the pick frequency assignment of SKUs to order picking zones (i.e., 2 zones (PF) and 4 zones (PF)). The number of visited locations decreases in combination with the savings batching policy. Orders within each zone are smaller, because the pick frequency zone assignment results in splitting orders across zones. So, within each order picking zone, the small orders are more likely be identical in terms of visited locations. These orders are combined more likely by the C\&W batching algorithm. Therefore, the number of visited locations strongly decreases while combining the savings batching algorithm with the pick frequency zone assignment.

Figure 8 further explains the relation between order batching and zone picking. Lines on the graph strongly converge when changing from a straightforward FCFS batching policy to more complex batching policies. The efficiency benefits resulting from zoning decrease in combination with smart batching algorithms compared to FCFS batching. SKUs on the pick list are diffused over the entire order picking area in case of strict order picking and FCFS batching. Batching policies resulting in short travel distances reduce the effect of zoning (e.g., varying zone picking policies show small 
route length differences in combination with seed batching). Moreover, increasing the number of zones, resulting in a smaller order picking area, reduces the effect of batching algorithms (e.g., the savings algorithm approximates the seed batching travel distance in combination with four zones). This can be explained by the fact that both batching and zoning aim to reduce the pick area during each pick round by combining equivalent orders and splitting the pick area, respectively.

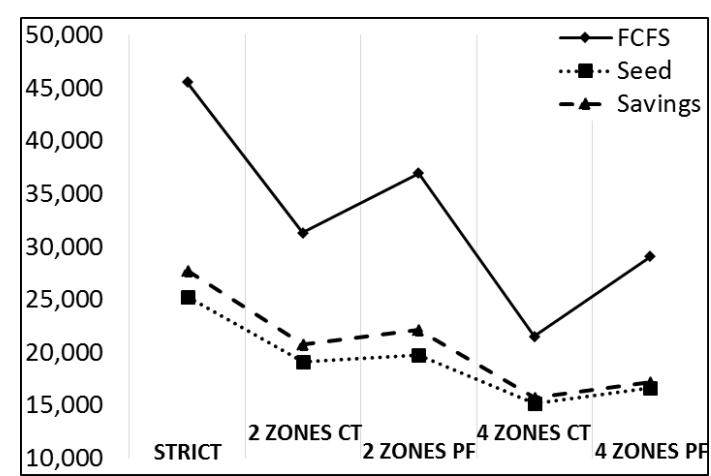

(a)

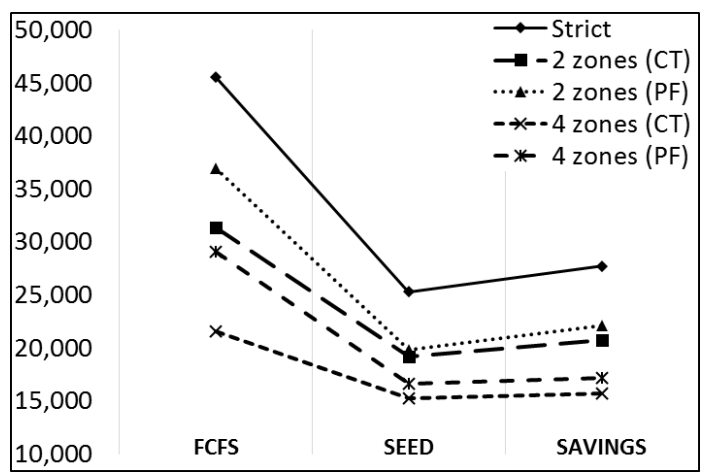

(b)

Figure 8: Average travel distance in meter for each combination of batching and zoning policy.

\subsubsection{Zone Picking and Picker Routing}

Finally, this section analyzes the currently unknown effect of combining the zone picking and routing planning problems. Hypothesis 6, that expects the joint effect of zoning and routing to be related, is tested using the full factorial repeated measures ANOVA on mean travel distance, the average number of pick rounds and the average number of visited locations. Based on the results shown in Tables 5, 6, and 7, the hypothesis is statistically supported: the joint effect of zone picking and picker routing on order picking performance is found to be statistically significant. Practical relevance lacks with respect to differences in number of pick rounds and number of visited locations.

Table 13: Post hoc multiple t-test for zoning policies by routing policies using Dunnett's method (familywise error rate $=0.01)$

\begin{tabular}{|c|c|c|c|c|c|c|c|c|c|}
\hline \multicolumn{2}{|c|}{ Strict } & \multicolumn{2}{|c|}{2 zones (CT) } & \multicolumn{2}{|c|}{2 zones (PF) } & \multicolumn{2}{|c|}{4 zones (CT) } & \multicolumn{2}{|c|}{4 zones $(\mathrm{PF})$} \\
\hline \multicolumn{10}{|c|}{ Travel distance (in meters) } \\
\hline R5 & 26,507 & R5 & 19,880 & $\mathrm{R} 5$ & 22,330 & R5 & 14,932 & R5 & 18,083 \\
\hline $\mathrm{R} 4$ & 32,495 & $\mathrm{R} 4$ & 23,674 & $\mathrm{R} 2$ & 25,869 & R4 & 17,467 & $\mathrm{R} 2$ & 20,904 \\
\hline $\mathrm{R} 2$ & 33,208 & $\mathrm{R} 2$ & 23,916 & $\mathrm{R} 4$ & 26,801 & $\mathrm{R} 2$ & 17,663 & $\mathrm{R} 4$ & 21,269 \\
\hline R3 & 34,375 & R3 & 24,939 & $\mathrm{R} 3$ & 27,957 & R3 & 18,107 & R3 & 21,869 \\
\hline $\mathrm{R} 1$ & 37,597 & $\mathrm{R} 1$ & 26,278 & $\mathrm{R} 1$ & 28,389 & $\mathrm{R} 1$ & 19,213 & $\mathrm{R} 1$ & 22,558 \\
\hline
\end{tabular}

$\mathrm{R} 1=$ aisle-by-aisle; $\mathrm{R} 2=$ traversal; $\mathrm{R} 3=$ return; $\mathrm{R} 4=$ largest gap; $\mathrm{R} 5=$ optimal

The results of the post hoc test decomposed in zone picking policies are summarized in Table 13. The different composition of subsets explains the statistical significance of the zone picking and picker routing planning problem. 


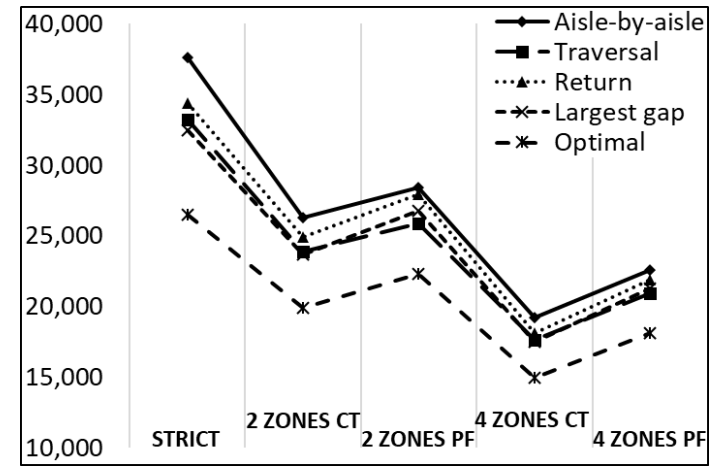

(a)

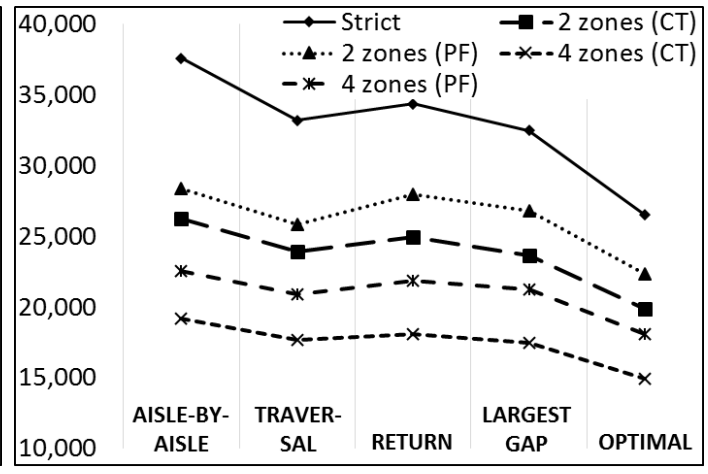

(b)

Figure 9: Average travel distance in meter for each combination of routing and zoning policy.

Again, the optimal routing policy is found to outperform all dedicated routing heuristics in combination with all zone picking policies. Since routing policies only determine the sequence of SKUs on the pick list, in other words, since SKUs on the pick list are distributed over the order picking area in the same way for all routing policies, the average route length differences between the routing policies increases as the pick area of a pick tour increases: decreasing the number of zones, slightly increases the effects of the routing policies as shown on Figure 9.

\subsection{Generalized Results}

In order to validate and generalize the results and findings of case study to other warehouses, other warehouse properties have been included in the second simulation experiment. The hypotheses formulated in Section 2.2 are tested and analyzed using the generalized experimental design. A $5 \times 3 \times 5 \times 5 \times 3 \times 3 \times 3$ full factorial mixed model ANOVA, with storage, batching, zoning, and routing as within-subjects factors is used to test the hypotheses and validate the results of the real-life case study. The ANOVA results are presented in Table A.1.

In accordance with the findings of the real-life case study, the results of the mixed model ANOVA show that the main effects of storage location assignment, order batching, zoning and routing are statistically significant. Furthermore, all six formulated hypotheses about the relations among the four order picking planning problems are statistically proven with respect to the distance traveled in Table A.1 of Appendix A. In addition to the real-life warehouse, the relations among storage, batching, zoning and routing are found to be statistically significantly related under varying warehouse layout, varying order size and varying batch capacity: warehouse layout, order size and batch capacity statistically significantly impact the joint effect of the order picking planning problems. Besides traveling, the six hypotheses are supported with respect to the number of pick rounds and the number of visited locations as well, as shown in Appendix A (Tables A.2 and A.3).

Results of the full factorial mixed model ANOVA on average travel distance indicate that the order picking layout, 
the order size and the batch capacity statistically significantly influence the relation between the order picking planning problems. Two examples that demonstrate the most clear interaction are discussed. Figure 10 illustrates the impact of order picking layout on the combination of zone picking and storage location assignment. The average travel distance for each combination of zoning and storage policy is shown for the three layout factor levels. The three interaction plots illustrate different patterns for each level of the order picking layout. The combined effect of zoning and storage strongly increases as the number of aisles in the order picking area increases. In case of 16 aisles, the pick frequency assignment of SKUs to order picking zones outperforms other zoning policies in combination with most storage location assignment policies. Increasing the number of aisles results in an increased travel distance of the pick frequency assignment compared to assigning SKUs to zones based on customer type in combination with all storage location assignment policies. This effect may be explained by the larger distance for traveling from the depot to the first storage location and returning to the depot at the end of a pick round. Assigning SKUs to order picking zones based on pick frequency results in an increased number of pick round due to orders splitting. So, orders pickers should travel more often to the depot compared to customer type zoning policies, and this travel distance has been increased in the 32 aisles and 48 aisles layout.

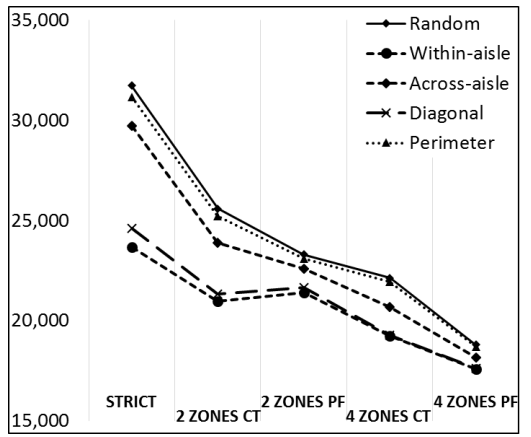

(a) Layout: 16 aisles.

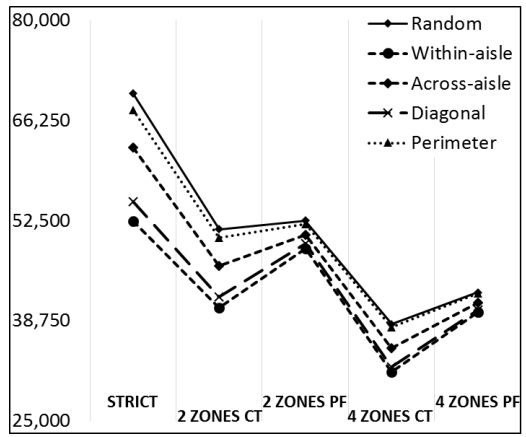

(b) Layout: 32 aisles

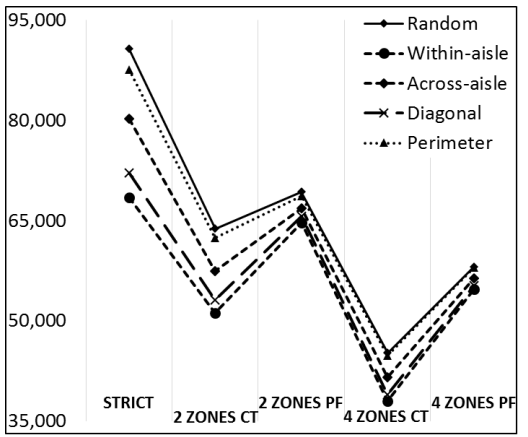

(c) Layout: 48 aisles.

Figure 10: Average travel distance (in meters) for each combination of zoning and storage policy.

In a second example, Figure 11 illustrates the impact of the capacity of the picking vehicle on the joint effect of batching and routing. The average travel distance resulting from the seed and savings algorithm under different routing policies are of particular interest. In case of a small batch capacity the savings algorithm results in a smaller route length in case of return, largest gap and optimal routing, whereas the route length differences are insignificant in combination with aisle-by-aisle and traversal routing. This effect reverses as the batch capacity increases. The seed algorithm outperforms the savings algorithm in combination with the aisle-based routing policies (i.e., aisle-by-aisle and traversal), while the mean route lengths are at the same level in combination with the other three routing policies. The seed selection and accompanying order selection rule under consideration aim to minimize the number of aisles to 
visit in a pick tour. Consequently, this seed algorithm favors the aisle-based routing policies. As the batch capacity increases, the efficiency of the basic Clarke-and-Wright variant slightly decreases: orders are combined in a pick tour based on large savings with a single order in the batch, but the combination with other orders that have already been assigned to the batch may be small (savings between orders are calculated only at the start of the algorithm). This effect is larger when a batch consist of a large number of orders. Consequently the savings algorithm is outperformed by the seed batching policy, at least in combination with aisle-based routing policies.

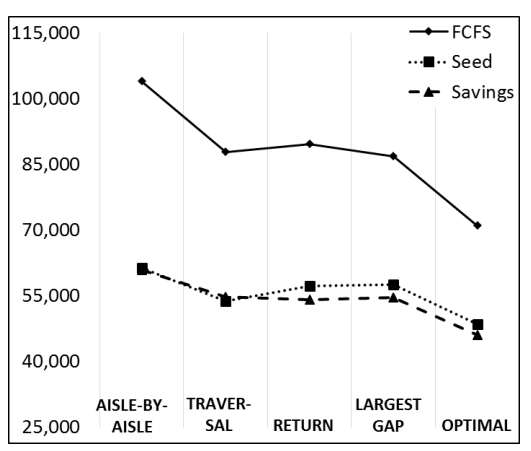

(a) Batch capacity: 10 orders.

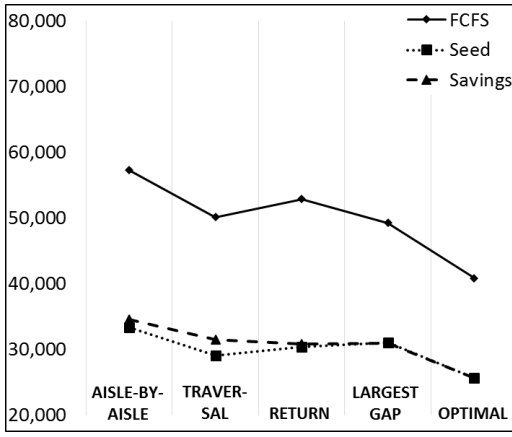

(b) Batch capacity: 25 orders.

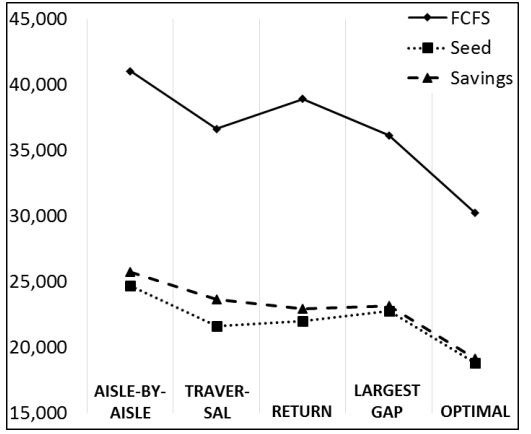

(c) Batch capacity: 40 orders.

Figure 11: Average travel distance (in meters) for each combination of batching and routing policy.

\section{Managerial Implications}

The results of the simulation experiments show the importance of combining storage, batching, zoning, and routing decisions in order to manage order picking activities efficiently. This section discusses the practical implications of this research for warehouse managers and provides policy combinations that help to improve the overall order picking performance in several practical situations.

Compared to the benchmark of the real-life warehouse (i.e., strict order picking in combination with random storage assignment, FCFS batching, and aisle-by-aisle routing), all proposed combinations perform better, except for the benchmark including perimeter instead of random storage. Over the 30 replications, the benchmark results in an average travel distance of 57,406 meter. The order picking process can be performed $79.3 \%$ more efficiently by dividing the warehouse into four order picking zones in combination with customer type zone assignment, within-aisle storage location assignment, savings batching, and optimal routing. This combination results in a mean route length of 11,886 meter. Note that the savings batching policy outperforms the seed batching policy in this specific combination in contrast to the previous discussed results.

Similar traveling savings $(77.9 \%)$ can be observed when evaluating the best performing combination (i.e., withinaisle storage, savings batching, 4 zones (CT), and optimal routing) and the benchmark policy combination in the 
context of the generalized case. Within-aisle storage, savings batching, 4 zones (CT), and optimal routing yields to a mean of 94.9 pick rounds and 3,268.6 visited locations, which is only $1.7 \%$ and $4.7 \%$ larger than the best performing policy combination in terms of 'number of pick rounds' and 'number of visited locations', respectively. In the discussion below, the overall best performing combination refers to the policy combination that yields the shortest mean route length: within-aisle storage, savings batching, 4 zones (CT), and optimal routing. As the simulation experiments have focused on operational order picking planning problems only, the proposed combinations are rather easy to implement and result in large performance benefits.

The applicability of the best performing combination is subject to several practical constraints that will be discussed below with respect to the simulation results of the generalized experiment. First, maintaining order integrity can not be generalized to all warehouses as not all warehouses can divide their orders across customer types. When SKUs are assigned to zones based on pick frequency (i.e., within-aisle storage, savings batching, 4 zones (PF), and optimal routing), the average route length increases by $18.8 \%$ compared to the best performing combination. Additionally, this combination of within-aisle storage, savings batching, 4 zones (PF) zoning and optimal routing, may result in sorting activities in case of parallel zone picking, an increased number of visited locations (6.4\%) and a strong increasing number of pick rounds $(39.4 \%)$ as orders are split across zones.

Second, the use of complex algorithms to solve the batching and routing planning problems have not been widely used in practice as calculating optimal batches and routes for each pick tour may require long computing times. In the context of the factor levels in this simulation study, the savings batching algorithm and LKH-routing heuristic (i.e., optimal) have a substantial impact on computing times compared to other batching and routing policies. Especially, the combination of savings batching and optimal routing requires a large amount of computing time. Furthermore, the effects of maverick picking prevent warehouses from using optimal routes to visit storage locations. Ignoring the savings and LKH-heuristic, the best performing policy combination includes within-aisle storage location assignment, seed batching, 4 zones (CT) zoning and traversal routing. This combination yields an increased route length of $15.0 \%$ and an increased number of visited locations of $5.4 \%$ compared to the overall best policy combination. The number of pick rounds remains similar.

Finally, the experiments under consideration assume a wide-aisle warehouse, disregarding aisle congestion. Narrowaisle picking systems are designed to increase storage capacity, but multiple order pickers may require to enter the same aisle which results in blocking of order pickers. The within-aisle and diagonal storage location assignment policy strongly concentrates picking activities in a small number of aisles, increasing the probability of picker blocking in aisles that mainly consist of class A locations. The probability of aisle congestion in narrow-aisle warehouses will be substantially smaller in combination with other storage policies as class A locations are diffused across pick aisles. An increased route length of only $9.6 \%$ compared to the overall best policy combination, can reduce efficiency losses 
due to aisle congestion. Moreover, the search time, in terms of number of visited locations, reduces with $2.7 \%$ and the setup time, in terms of number of pick rounds, is similar compared to the overall best policy combination. So, in narrow-aisle warehouses, the combination of across-aisle storage, savings batching, 4 zones (CT) and optimal routing can improve the overall order picking performance as within-aisle and diagonal storage are expected to result in aisle congestion.

In addition, the simulation results provide insights into the relations among storage, batching, zone picking, and routing. In contrast to previous studies (see Table 2), all main effects as well as all interaction effects have been proven to be statistically significant. Warehouse managers should take these interactions among order picking planning problems into account to design efficient order picking systems. For example, zone picking increases pick efficiency substantially, but reduces potential efficiency benefits resulting from optimizing other order picking planning problems. Furthermore, policies for each planning problem need to aim at increasing the pick density in the same area of the warehouse to reduce traveling: examples are the combination of the cumulative seed batching algorithm and traversal routing, seed batching in combination with within-aisle storage classes, and return routes combined with across-aisle storage. Warehouse managers should be aware of the strong relations among order picking planning problems in order to optimize the overall warehouse performance.

\section{Conclusions}

Serving e-commerce markets forces warehouses to handle a growing number of orders in shorter time windows. Awareness of the influence of an individual warehouse operation on the overall warehouse performance is required to manage warehouse operations more efficiently, resulting in enhanced customer service.

In this paper, the relations among the storage, batching, zone picking, and routing planning problems are analyzed and explained for the first time. The simulation results of our study contribute to both practitioners and the scientific community. The results of the study clearly indicate that warehouses can achieve significant benefits by considering storage, batching, zone picking, and routing decisions simultaneously. The simulation results and statistical analysis provides policy combinations that help practitioners to improve the overall order picking performance in several practical situations. The simulated order picking policies can be easily implemented and immediately result in significant performance benefits. Furthermore, this paper is able to statistically prove that all relations among the four main order picking planning problems are statistically significant. Additionally, by evaluating an extensive range of policies for each order picking planning problem, the relations among the planning problems are explained.

Below we formulate several research opportunities that are highly relevant to practice, but largely unexplored in academic literature. The results of this study show that future research should focus on combining planning problems, 
while providing new solution methods. A need remains to integrate more planning problems (e.g., workforce planning) and additionally account for real-life characteristics, such as precedence constraints (i.e., requiring certain products to be retrieved before other products due to weight restrictions, fragility, and shape), real time order arrival, and assigning fast moving SKUs to multiple storage locations. Incorporating these real-life characteristics and constraints while developing new efficient solution methods for a combined order picking planning problem will make academic research more valuable to warehouses serving e-commerce customers.

\section{Acknowledgments.}

This work is supported by the Interuniversity Attraction Poles Program initiated by the Belgian Science Policy Office (research project COMEX, Combinatorial Optimization: Metaheuristics \& Exact Methods).

The computational resources and services used in this work were provided by the VSC (Flemish Supercomputer Center), funded by the Research Foundation - Flanders (FWO) and the Flemish Government department EWI.

\section{References}

Baker, P., Canessa, M., 2009. Warehouse design: A structured approach. European Journal of Operational Research 193 (2), $425-436$.

Chackelson, C., Errasti, A., Ciprs, D., Lahoz, F., 2013. Evaluating order picking performance trade-offs by configuring main operating strategies in a retail distributor: A Design of Experiments approach. International Journal of Production Research 51 (20), 6097-6109.

Chen, C.-M., Gong, Y., De Koster, R. B. M., Van Nunen, J. A., Feb. 2010. A Flexible Evaluative Framework for Order Picking Systems. Production \& Operations Management 19 (1), 70-82.

Chen, T.-L., Cheng, C.-Y., Chen, Y.-Y., Chan, L.-K., Jan. 2015. An efficient hybrid algorithm for integrated order batching, sequencing and routing problem. International Journal of Production Economics 159, 158-167.

Cheng, C.-Y., Chen, Y.-Y., Chen, T.-L., Jung-Woon Yoo, J., Dec. 2015. Using a hybrid approach based on the particle swarm optimization and ant colony optimization to solve a joint order batching and picker routing problem. International Journal of Production Economics 170 , Part C, $805-814$.

Clarke, G. U., Wright, J. W., 1964. Scheduling of vehicles from a central depot to a number of delivery points. Operations research 12 (4), 568-581.

Cohen, B. H., Welkowitz, J., Lea, R. B., 2011. Introductory Statistics for the Behavioral Sciences (7th Edition). John Wiley \& Sons, Hoboken, NJ, USA.

Dallari, F., Marchet, G., Melacini, M., 2009. Design of order picking system. The International Journal of Advanced Manufacturing Technology $42(1-2), 1-12$.

Davarzani, H., Norrman, A., Jan. 2015. Toward a relevant agenda for warehousing research: literature review and practitioners' input. Logistics Research 8 (1), 1-18.

De Koster, R. B. M., Le-Duc, T., Roodbergen, K. J., Oct. 2007. Design and control of warehouse order picking: A literature review. European Journal of Operational Research $182(2), 481-501$.

De Koster, R. B. M., Le-Duc, T., Zaerpour, N., 2012. Determining the number of zones in a pick-and-sort order picking system. International Journal of Production Research 50 (3), 757-771. 
De Koster, R. B. M., Van der Poort, E. S., Wolters, M., May 1999. Efficient orderbatching methods in warehouses. International Journal of Production Research 37 (7), 1479.

Elbert, R. M., Franzke, T., Glock, C. H., Grosse, E. H., Sep. 2017. The effects of human behavior on the efficiency of routing policies in order picking: The case of route deviations. Computers \& Industrial Engineering 111, 537-551.

Field, A., Feb. 2013. Discovering Statistics using IBM SPSS Statistics. SAGE.

Gademann, N., Van de Velde, S., Jan. 2005. Order batching to minimize total travel time in a parallel-aisle warehouse. IIE Transactions 37 (1), $63-75$.

Geisser, S., Greenhouse, S. W., 1958. An extension of box's results on the use of the f distribution in multivariate analysis. The Annals of Mathematical Statistics 29 (3), 885-891.

Giannikas, V., Lu, W., Robertson, B., McFarlane, D., Jul. 2017. An interventionist strategy for warehouse order picking: Evidence from two case studies. International Journal of Production Economics 189, 63-76.

Glock, C. H., Grosse, E. H., Elbert, R. M., Franzke, T., Nov. 2016. Maverick picking: the impact of modifications in work schedules on manual order picking processes. International Journal of Production Research 0 (0), 1-17.

Gong, Y., De Koster, R. B. M., Oct. 2011. A review on stochastic models and analysis of warehouse operations. Logistics Research 3 (4), $191-205$.

Gu, J., Goetschalckx, M., McGinnis, L. F., Feb. 2007. Research on warehouse operation: A comprehensive review. European Journal of Operational Research 177 (1), 1-21.

Guo, X., Yu, Y., De Koster, R. B. M., 2016. Impact of required storage space on storage policy performance in a unit-load warehouse. International Journal of Production Research 54 (8), 1-14.

Helsgaun, K., 2000. An effective implementation of the LinKernighan traveling salesman heuristic. European Journal of Operational Research 126 (1), 106-130.

Henn, S., Koch, S. r., Wäscher, G., 2012. Order Batching in Order Picking Warehouses: A Survey of Solution Approaches. In: Manzini, R. (Ed.), Warehousing in the Global Supply Chain. Springer London, pp. 105-137.

Ho, Y.-C., Lin, J.-W., 2017. Improving Order-Picking Performance by Converting a Sequential Zone-Picking Line into a Zone-Picking Network. forthcomming in Computers \& Industrial Engineering.

Ho, Y.-C., Su, T.-S., Shi, Z.-B., Sep. 2008. Order-batching methods for an order-picking warehouse with two cross aisles. Computers \& Industrial Engineering $55(2), 321-347$.

Ho, Y.-C., Tseng, Y.-Y., 2006. A study on order-batching methods of order-picking in a distribution centre with two cross-aisles. International Journal of Production Research 44 (17), 3391-3417.

Hsieh, L.-F., Tsai, L., May 2006. The optimum design of a warehouse system on order picking efficiency. The International Journal of Advanced Manufacturing Technology 28 (5-6), 626-637.

Jane, C.-C., Laih, Y.-W., Oct. 2005. A clustering algorithm for item assignment in a synchronized zone order picking system. European Journal of Operational Research 166 (2), 489-496.

Kulak, O., Sahin, Y., Taner, M. E., Mar. 2012. Joint order batching and picker routing in single and multiple-cross-aisle warehouses using clusterbased tabu search algorithms. Flexible Services and Manufacturing Journal 24 (1), 52-80.

Manzini, R., Accorsi, R., Gamberi, M., Penazzi, S., 2015. Modeling class-based storage assignment over life cycle picking patterns. International Journal of Production Economics 170, Part C, 790-800. 
Manzini, R., Gamberi, M., Persona, A., Regattieri, A., 2007. Design of a class based storage picker to product order picking system. The International Journal of Advanced Manufacturing Technology 32 (7-8), 811-821.

Marchet, G., Melacini, M., Perotti, S., Jan. 2015. Investigating order picking system adoption: a case-study-based approach. International Journal of Logistics Research and Applications 18 (1), 82-98.

Muter, b., Öncan, T., 2015. An exact solution approach for the order batching problem. IIE Transactions 47 (7), $728-738$.

Petersen, C. G., 2000. An evaluation of order picking policies for mail order companies. Production and Operations Management 9 (4), 319-335.

Petersen, C. G., Jul. 2002. Considerations in order picking zone configuration. International Journal of Operations \& Production Management $22(7), 793-805$.

Petersen, C. G., Aase, G., Nov. 2004. A comparison of picking, storage, and routing policies in manual order picking. International Journal of Production Economics 92 (1), 11-19.

Petersen, C. G., Schmenner, R. W., Mar. 1999. An Evaluation of Routing and Volume-based Storage Policies in an Order Picking Operation. Decision Sciences $30(2), 481-501$.

Quader, S., Castillo-Villar, K. K., 2017. Design of an enhanced multi-aisle order-picking system considering storage assignments and routing heuristics. Robotics and Computer-Integrated Manufacturing.

Roodbergen, K. J., 2012. Storage Assignment for Order Picking in Multiple-Block Warehouses. In: Manzini, R. (Ed.), Warehousing in the Global Supply Chain. Springer London, pp. 139-155.

Roodbergen, K. J., De Koster, R. B. M., Jun. 2001. Routing methods for warehouses with multiple cross aisles. International Journal of Production Research 39 (9), 1865-1883.

Ruben, R. A., Jacobs, F. R., Apr. 1999. Batch Construction Heuristics and Storage Assignment Strategies for Walk/Ride and Pick Systems. Management Science 45 (4), 575-596.

Scholz, A., Henn, S., Stuhlmann, M., Wäscher, G., 2016. A New Mathematical Programming Formulation for the Single-Picker Routing Problem. European Journal of Operational Research 253 (1), 68-84.

Shqair, M., Altarazi, S., Al-Shihabi, S., Dec. 2014. A statistical study employing agent-based modeling to estimate the effects of different warehouse parameters on the distance traveled in warehouses. Simulation Modelling Practice and Theory 49, $122-135$.

Sprock, T., Murrenhoff, A., McGinnis, L. F., 2016. A hierarchical approach to warehouse design. International Journal of Production Research $0(0), 1-13$.

Theys, C., Bräysy, O., Dullaert, W., Raa, B., Feb. 2010. Using a TSP heuristic for routing order pickers in warehouses. European Journal of Operational Research 200 (3), 755-763.

Tompkins, J. A., White, J. A., Bozer, Y. A., Tanchoco, J. M. A., Jan. 2010. Facilities Planning. John Wiley \& Sons.

Van Gils, T., Braekers, K., Ramaekers, K., Depaire, B., Caris, A., Sep. 2016. Improving Order Picking Efficiency by Analyzing Combinations of Storage, Batching, Zoning, and Routing Policies. In: Paias, A., Ruthmair, M., Voß, S. (Eds.), Lecture Notes in Computational Logistics. No. 9855 in Lecture Notes in Computer Science. Springer International Publishing, pp. 427-442.

Van Gils, T., Ramaekers, K., Caris, A., De Koster, R. B. M., 2017. Designing Efficient Order Picking Systems by Combining Planning Problems: State-of-the-art Classification and Review. forthcomming in European Journal of Operational Research.

Won, J., Olafsson, S., 2005. Joint order batching and order picking in warehouse operations. International Journal of Production Research 43 (7), $1427-1442$. 
Yu, M., De Koster, R. B. M., Oct. 2009. The impact of order batching and picking area zoning on order picking system performance. European Journal of Operational Research 198 (2), 480-490.

Yu, Y., De Koster, R. B. M., Guo, X., Aug. 2015. Class-Based Storage with a Finite Number of Items: Using More Classes is not Always Better. Production and Operations Management 24 (8), 1235-1247.

\section{A ANOVA Results of the Generalized Case}


Table A.1: $5 \times 3 \times 5 \times 5 \times 3 \times 3 \times 3$ full factorial mixed model ANOVA on average travel distance

\begin{tabular}{|c|c|c|c|c|c|}
\hline & Sum of squares & df & Mean square & $F$ & $p$-value \\
\hline \multicolumn{6}{|l|}{ Main effects } \\
\hline Storage & $2,581,068,182,161$ & 1.15 & $2,252,145,769,126$ & $20,840.87$ & 0.000 \\
\hline Batching & $33,580,344,072,124$ & 1.09 & $30,777,152,758,560$ & $72,464.62$ & 0.000 \\
\hline Zoning & $19,861,136,109,911$ & 1.14 & $17,471,263,744,616$ & $17,310.27$ & 0.000 \\
\hline Routing & $5,238,742,190,582$ & 1.16 & $4,523,368,614,508$ & $7,933.50$ & 0.000 \\
\hline Layout & $74,889,003,015,144$ & 2.00 & $37,444,501,507,572$ & $1,369.28$ & 0.000 \\
\hline Order size & $39,478,612,491,554$ & 2.00 & $19,738,306,245,777$ & 721.83 & 0.000 \\
\hline Capacity & $82,120,906,136,649$ & 2.00 & $41,060,453,068,325$ & $1,501.50$ & 0.000 \\
\hline \multicolumn{6}{|l|}{ Two-way interaction } \\
\hline Storage $\times$ batching & $90,300,439,821$ & 2.72 & $33,163,221,224$ & $7,782.71$ & 0.000 \\
\hline Storage $\times$ zoning & $1,127,150,536,133$ & 2.85 & $395,129,511,299$ & $21,247.75$ & 0.000 \\
\hline Storage $\times$ routing & $870,166,236,240$ & 1.18 & $736,466,291,737$ & $5,826.79$ & 0.000 \\
\hline Storage $\times$ layout & $310,780,615,930$ & 2.29 & $135,587,903,902$ & $1,254.70$ & 0.000 \\
\hline Storage $\times$ order size & $229,692,149,974$ & 2.29 & $100,210,487,918$ & 927.33 & 0.000 \\
\hline Storage $\times$ capacity & $442,422,460,243$ & 2.29 & $193,020,835,112$ & $1,786.17$ & 0.000 \\
\hline Batching $\times$ zoning & $2,387,900,915,031$ & 1.66 & $1,438,432,735,742$ & $18,445.89$ & 0.000 \\
\hline Batching $\times$ routing & $899,200,878,940$ & 1.82 & $493,131,569,186$ & $7,926.60$ & 0.000 \\
\hline Batching $\times$ layout & $175,621,334,192$ & 2.18 & $80,480,483,143$ & 189.49 & 0.000 \\
\hline Batching $\times$ order size & $1,608,240,071,395$ & 2.18 & $736,994,389,388$ & $1,735.25$ & 0.000 \\
\hline Batching $\times$ capacity & $4,287,191,394,336$ & 2.18 & $1,964,654,444,357$ & $4,625.77$ & 0.000 \\
\hline Zoning $\times$ routing & $601,576,392,051$ & 1.70 & $354,441,334,759$ & $3,827.88$ & 0.000 \\
\hline Zoning $\times$ layout & $5,536,682,301,049$ & 2.27 & $2,435,229,188,715$ & $2,412.79$ & 0.000 \\
\hline Zoning $\times$ order size & $1,195,409,824,188$ & 2.27 & $525,783,626,015$ & 520.94 & 0.000 \\
\hline Zoning $\times$ capacity & $1,220,803,943,468$ & 2.27 & $536,952,860,067$ & 532.00 & 0.000 \\
\hline Routing $\times$ layout & $960,958,655,058$ & 2.32 & $414,867,735,612$ & 727.63 & 0.000 \\
\hline Routing $\times$ order size & $495,592,132,807$ & 2.32 & $213,958,410,014$ & 375.26 & 0.000 \\
\hline Routing $\times$ capacity & $849,590,082,014$ & 2.32 & $366,787,386,397$ & 643.31 & 0.000 \\
\hline \multicolumn{6}{|l|}{ Three-way interaction } \\
\hline Storage $\times$ batching $\times$ layout & $30,094,322,817$ & 5.45 & $5,526,134,131$ & $1,296.87$ & 0.000 \\
\hline Storage $\times$ batching $\times$ order size & $7,327,980,133$ & 5.45 & $1,345,615,961$ & 315.79 & 0.000 \\
\hline Storage $\times$ batching $\times$ capacity & $8,078,527,577$ & 5.45 & $1,483,436,834$ & 348.13 & 0.000 \\
\hline Storage $\times$ zoning $\times$ layout & $148,682,239,997$ & 5.71 & $26,060,734,101$ & $1,401.39$ & 0.000 \\
\hline Storage $\times$ zoning $\times$ order size & $72,210,421,440$ & 5.71 & $12,656,902,347$ & 680.61 & 0.000 \\
\hline Storage $\times$ zoning $\times$ capacity & $136,145,313,898$ & 5.71 & $23,863,286,057$ & $1,283.23$ & 0.000 \\
\hline Storage $\times$ routing $\times$ layout & $217,727,481,050$ & 2.36 & $92,136,964,122$ & 728.97 & 0.000 \\
\hline Storage $\times$ routing $\times$ order size & $99,862,577,377$ & 2.36 & $42,259,409,169$ & 334.35 & 0.000 \\
\hline Storage $\times$ routing $\times$ capacity & $128,873,750,445$ & 2.36 & $54,536,230,630$ & 431.48 & 0.000 \\
\hline Batching $\times$ zoning $\times$ layout & $319,921,189,170$ & 3.32 & $96,357,664,689$ & $1,235.65$ & 0.000 \\
\hline Batching $\times$ zoning $\times$ order size & $85,706,172,600$ & 3.32 & $25,814,003,325$ & 331.03 & 0.000 \\
\hline Batching $\times$ zoning $\times$ capacity & $150,824,386,979$ & 3.32 & $45,427,080,792$ & 582.54 & 0.000 \\
\hline Batching $\times$ routing $\times$ layout & $106,622,591,114$ & 3.65 & $29,236,495,925$ & 469.95 & 0.000 \\
\hline Batching $\times$ routing $\times$ order size & $97,750,542,763$ & 3.65 & $26,803,731,886$ & 430.84 & 0.000 \\
\hline Batching $\times$ routing $\times$ capacity & $283,493,086,062$ & 3.65 & $77,735,350,163$ & $1,249.52$ & 0.000 \\
\hline Zoning $\times$ routing $\times$ layout & $175,812,536,365$ & 3.39 & $51,793,280,853$ & 559.35 & 0.000 \\
\hline Zoning $\times$ routing $\times$ order size & $72,975,231,492$ & 3.39 & $21,498,049,787$ & 232.17 & 0.000 \\
\hline Zoning $\times$ routing $\times$ capacity & $101,062,411,459$ & 3.39 & $29,772,358,494$ & 321.53 & 0.000 \\
\hline \multicolumn{6}{|l|}{ Residuals } \\
\hline Between subjects & $21,959,012,878,673$ & 803.00 & $27,346,217,782$ & & \\
\hline Within storage & $99,448,725,278$ & 920.28 & $108,063,914$ & & \\
\hline Within batching & $372,112,852,007$ & 876.14 & $424,719,717$ & & \\
\hline Within zoning & $921,331,257,435$ & 912.84 & $1,009,300,509$ & & \\
\hline Within routing & $530,246,091,529$ & 929.99 & 570160182 & & \\
\hline Within storage $\times$ batching & $9,316,966,516$ & $2,186.50$ & $4,261,140$ & & \\
\hline Within storage $\times$ zoning & $42,597,531,064$ & $2,290.65$ & $18,596,295$ & & \\
\hline Within storage $\times$ routing & $119,919,087,590$ & 948.78 & $126,393,115$ & & \\
\hline Within batching $\times$ zoning & $103,951,845,341$ & $1,333.04$ & $77,981,200$ & & \\
\hline Within batching $\times$ routing & $91,093,082,051$ & $1,464.23$ & $62,212,254$ & & \\
\hline Within zoning $\times$ routing & $126,196,678,465$ & $1,362.89$ & $92,594,663$ & & \\
\hline Total & $307,657,490,319,680$ & $14,149.62$ & & & \\
\hline
\end{tabular}


Table A. $2: 5 \times 3 \times 5 \times 5 \times 3 \times 3 \times 3$ full factorial mixed model ANOVA on average number of pick rounds

\begin{tabular}{|c|c|c|c|c|c|}
\hline & Sum of squares & df & Mean square & $F$ & $p$-value \\
\hline \multicolumn{6}{|l|}{ Main effects } \\
\hline Storage & 150.3 & 3.63 & 41.43 & 487.16 & 0.000 \\
\hline Batching & $6,210.55$ & 1.00 & $6,210.55$ & $2,728.06$ & 0.000 \\
\hline Zoning & $67,629,631.93$ & 1.01 & $67,142,707.71$ & $4,228.23$ & 0.000 \\
\hline Routing & 746.94 & 1.33 & 560.85 & 520.18 & 0.000 \\
\hline Layout & $17,551,278.69$ & 2.00 & $8,775,639.34$ & $1,145.66$ & 0.000 \\
\hline Order size & $2,369.04$ & 2.00 & $1,184.52$ & 0.15 & 0.857 \\
\hline Capacity & $1,120,342,143.36$ & 2.00 & $560,171,071.70$ & $73,130.43$ & 0.000 \\
\hline \multicolumn{6}{|l|}{ Two-way interaction } \\
\hline Storage $\times$ batching & 300.59 & 3.63 & 82.86 & 487.16 & 0.000 \\
\hline Storage $\times$ zoning & 12.31 & 14.49 & 0.85 & 11.75 & 0.000 \\
\hline Storage $\times$ routing & 433.40 & 7.06 & 61.39 & 426.50 & 0.000 \\
\hline Storage $\times$ layout & 92.21 & 7.26 & 12.71 & 149.44 & 0.000 \\
\hline Storage $\times$ order size & 3.72 & 7.26 & 0.51 & 6.03 & 0.000 \\
\hline Storage $\times$ capacity & 81.94 & 7.26 & 11.29 & 132.79 & 0.000 \\
\hline Batching $\times$ zoning & 188.81 & 3.43 & 55.07 & 73.56 & 0.000 \\
\hline Batching $\times$ routing & $1,493.88$ & 1.33 & $1,121.71$ & 520.18 & 0.000 \\
\hline Batching $\times$ layout & $4,146.89$ & 2.00 & $2,073.45$ & 910.79 & 0.000 \\
\hline Batching $\times$ order size & 0.69 & 2.00 & 0.35 & 0.15 & 0.859 \\
\hline Batching $\times$ capacity & $3,965.90$ & 2.00 & $1,982.95$ & 871.03 & 0.000 \\
\hline Zoning $\times$ routing & 140.40 & 9.60 & 14.62 & 130.69 & 0.000 \\
\hline Zoning $\times$ layout & $36,910,024.70$ & 2.01 & $18,322,138.75$ & $1,153.81$ & 0.000 \\
\hline Zoning $\times$ order size & $4,090.18$ & 2.01 & $2,030.37$ & 0.13 & 0.881 \\
\hline Zoning $\times$ capacity & $22,406,700.93$ & 2.01 & $11,122,687.85$ & 700.44 & 0.000 \\
\hline Routing $\times$ layout & 764.01 & 2.66 & 286.83 & 266.03 & 0.000 \\
\hline Routing $\times$ order size & 279.37 & 2.66 & 104.89 & 97.28 & 0.000 \\
\hline Routing $\times$ capacity & 534.64 & 2.66 & 200.72 & 186.16 & 0.000 \\
\hline \multicolumn{6}{|l|}{ Three-way interaction } \\
\hline Storage $\times$ batching $\times$ layout & 184.42 & 7.26 & 25.42 & 149.44 & 0.000 \\
\hline Storage $\times$ batching $\times$ order size & 7.44 & 7.26 & 1.03 & 6.03 & 0.000 \\
\hline Storage $\times$ batching $\times$ capacity & 163.87 & 7.26 & 22.59 & 132.79 & 0.000 \\
\hline Storage $\times$ zoning $\times$ layout & 17.26 & 28.99 & 0.60 & 8.23 & 0.000 \\
\hline Storage $\times$ zoning $\times$ order size & 6.81 & 28.99 & 0.23 & 3.25 & 0.000 \\
\hline Storage $\times$ zoning $\times$ capacity & 15.83 & 28.99 & 0.55 & 7.55 & 0.000 \\
\hline Storage $\times$ routing $\times$ layout & 431.97 & 14.12 & 30.59 & 212.55 & 0.000 \\
\hline Storage $\times$ routing $\times$ order size & 16.37 & 14.12 & 1.16 & 8.05 & 0.000 \\
\hline Storage $\times$ routing $\times$ capacity & 210.05 & 14.12 & 14.88 & 103.35 & 0.000 \\
\hline Batching $\times$ zoning $\times$ layout & 162.89 & 6.86 & 23.75 & 31.73 & 0.000 \\
\hline Batching $\times$ zoning $\times$ order size & 11.40 & 6.86 & 1.66 & 2.22 & 0.031 \\
\hline Batching $\times$ zoning $\times$ capacity & 286.02 & 6.86 & 41.71 & 55.71 & 0.000 \\
\hline Batching $\times$ routing $\times$ layout & $1,528.02$ & 2.66 & 573.67 & 266.03 & 0.000 \\
\hline Batching $\times$ routing $\times$ order size & 558.75 & 2.66 & 209.77 & 97.28 & 0.000 \\
\hline Batching $\times$ routing $\times$ capacity & $1,069.27$ & 2.66 & 401.44 & 186.16 & 0.000 \\
\hline Zoning $\times$ routing $\times$ layout & 60.88 & 19.21 & 3.17 & 28.33 & 0.000 \\
\hline Zoning $\times$ routing $\times$ order size & 47.77 & 19.21 & 2.49 & 22.23 & 0.000 \\
\hline Zoning $\times$ routing $\times$ capacity & 130.41 & 19.21 & 6.79 & 60.70 & 0.000 \\
\hline \multicolumn{6}{|l|}{ Residuals } \\
\hline Between subjects & $6,150,892.20$ & 803.00 & $7,659.89$ & & \\
\hline Within storage & 247.74 & $2,913.18$ & 0.09 & & \\
\hline Within batching & $1,828.07$ & 803.00 & 2.28 & & \\
\hline Within zoning & $12,843,816.58$ & 808.82 & $15,879.63$ & & \\
\hline Within routing & $1,153.05$ & $1,069.43$ & 1.08 & & \\
\hline Within storage $\times$ batching & 495.47 & $2,913.18$ & 0.17 & & \\
\hline Within storage $\times$ zoning & 841.39 & $11,639.17$ & 0.07 & & \\
\hline Within storage $\times$ routing & 815.99 & $5,669.34$ & 0.14 & & \\
\hline Within batching $\times$ zoning & $2,061.14$ & $2,753.16$ & 0.75 & & \\
\hline Within batching $\times$ routing & $2,306.10$ & $1,069.43$ & 2.16 & & \\
\hline Within zoning $\times$ routing & 862.69 & $7,711.03$ & 0.11 & & \\
\hline Total & $1,283,876,015.20$ & $38,484,33$ & & & \\
\hline
\end{tabular}


Table A.3: $5 \times 3 \times 5 \times 5 \times 3 \times 3 \times 3$ full factorial mixed model ANOVA on average number of visited locations

\begin{tabular}{|c|c|c|c|c|c|}
\hline & Sum of squares & df & Mean square & $F$ & $p$-value \\
\hline \multicolumn{6}{|l|}{ Main effects } \\
\hline Storage & $583,256,129$ & 2.17 & $268,469,533$ & $23,436.92$ & 0.000 \\
\hline Batching & $38,366,624,020$ & 1.43 & $26,776,029,650$ & $122,256.41$ & 0.000 \\
\hline Zoning & $13,301,802,850$ & 1.09 & $12,240,001,150$ & $10,408.60$ & 0.000 \\
\hline Routing & $87,602,723$ & 2.19 & $40,090,608$ & $14,842.89$ & 0.000 \\
\hline Layout & $1,356,917,368,476$ & 2.00 & $678,458,684,200$ & $1,145.66$ & 0.000 \\
\hline Order size & $27,903,628,050$ & 2.00 & $13,951,814,030$ & 396.90 & 0.000 \\
\hline Capacity & $29,710,345,870$ & 2.00 & $14,855,172,940$ & 422.60 & 0.000 \\
\hline \multicolumn{6}{|l|}{ Two-way interaction } \\
\hline Storage $\times$ batching & $379,340,557$ & 4.52 & $83,890,741$ & $13,865.63$ & 0.000 \\
\hline Storage $\times$ zoning & $125,139,890$ & 13.17 & $9,498,546$ & $2,798.71$ & 0.000 \\
\hline Storage $\times$ routing & $4,211,097$ & 12.66 & 332,756 & $1,043.79$ & 0.000 \\
\hline Storage $\times$ layout & $9,184,924$ & 4.35 & $2,113,884$ & 184.54 & 0.000 \\
\hline Storage $\times$ order size & 874,018 & 4.35 & 201,153 & 17,56 & 0.000 \\
\hline Storage $\times$ capacity & $20,661,118$ & 4.35 & $4,755,098$ & 415.11 & 0.000 \\
\hline Batching $\times$ zoning & $847,489,156$ & 2.32 & $365,496,385$ & $5,450.48$ & 0.000 \\
\hline Batching $\times$ routing & $175,205,446$ & 2.19 & $80,181,216$ & $14,842.89$ & 0.000 \\
\hline Batching $\times$ layout & $1,856,955,772$ & 2.87 & $647,983,815$ & $2,958.62$ & 0.000 \\
\hline Batching $\times$ order size & $775,399,337$ & 2.87 & $270,575,222$ & $1,235.42$ & 0.000 \\
\hline Batching $\times$ capacity & $549,133,249$ & 2.87 & $191,619,781$ & 874.91 & 0.000 \\
\hline Zoning $\times$ routing & $8,395,813$ & 5.37 & $1,563,276$ & $1,476.54$ & 0.000 \\
\hline Zoning $\times$ layout & $8,808,436,813$ & 2.17 & $4,052,656,544$ & $3,446.28$ & 0.000 \\
\hline Zoning $\times$ order size & $446,264,356$ & 2.17 & $205,320,899$ & 174.60 & 0.000 \\
\hline Zoning $\times$ capacity & $1,278,070,760$ & 2.17 & $588,025,088$ & 500.04 & 0.000 \\
\hline Routing $\times$ layout & $25,184,737$ & 4.37 & $5,762,786$ & $2,133.58$ & 0.000 \\
\hline Routing $\times$ order size & $1,228,155$ & 4.37 & 281,027 & 104.05 & 0.000 \\
\hline Routing $\times$ capacity & $4,745,661$ & 4.37 & $1,085,905$ & 402.04 & 0.000 \\
\hline \multicolumn{6}{|l|}{ Three-way interaction } \\
\hline Storage $\times$ batching $\times$ layout & $13,497,586$ & 9.04 & $1,492,488$ & 246.68 & 0.000 \\
\hline Storage $\times$ batching $\times$ order size & $6,385,266$ & 9.04 & 706,047 & 116.70 & 0.000 \\
\hline Storage $\times$ batching $\times$ capacity & $12,946,125$ & 9.04 & $1,431,511$ & 236.60 & 0.000 \\
\hline Storage $\times$ zoning $\times$ layout & $9,340,857$ & 26.35 & 354,502 & 104.45 & 0.000 \\
\hline Storage $\times$ zoning $\times$ order size & $4,051,851$ & 26.35 & 153,775 & 45.31 & 0.000 \\
\hline Storage $\times$ zoning $\times$ capacity & $3,874,850$ & 26.35 & 147,057 & 43.33 & 0.000 \\
\hline Storage $\times$ routing $\times$ layout & $50,369,473$ & 4.37 & $11,525,571$ & $2,133.58$ & 0.000 \\
\hline Storage $\times$ routing $\times$ order size & $2,456,310$ & 4.37 & 562,054 & 104.05 & 0.000 \\
\hline Storage $\times$ routing $\times$ capacity & $9,491,323$ & 4.37 & $2,171,810$ & 402.04 & 0.000 \\
\hline Batching $\times$ zoning $\times$ layout & $498,429,683$ & 4.64 & $107,478,807$ & $1,602.78$ & 0.000 \\
\hline Batching $\times$ zoning $\times$ order size & $114,260,744$ & 4.64 & $24,638,598$ & 367.42 & 0.000 \\
\hline Batching $\times$ zoning $\times$ capacity & $101,586,353$ & 4.64 & $21,905,557$ & 326.67 & 0.000 \\
\hline Batching $\times$ routing $\times$ layout & $50,369,473$ & 4.37 & $11,525,571$ & $2,133.58$ & 0.000 \\
\hline Batching $\times$ routing $\times$ order size & $2,456,310$ & 4.37 & 562,054 & 104.05 & 0.000 \\
\hline Batching $\times$ routing $\times$ capacity & $9,491,323$ & 4.37 & $2,171,810$ & 402.04 & 0.000 \\
\hline Zoning $\times$ routing $\times$ layout & $6,203,159$ & 10.74 & 577,505 & 545.46 & 0.000 \\
\hline Zoning $\times$ routing $\times$ order size & $1,811,831$ & 10.74 & 168,679 & 159.32 & 0.000 \\
\hline Zoning $\times$ routing $\times$ capacity & 316,780 & 10.74 & 29,492 & 27.86 & 0.000 \\
\hline \multicolumn{6}{|l|}{ Residuals } \\
\hline Between subjects & $28,226,772,140$ & 803.00 & $35,151,646$ & & \\
\hline Within storage & $19,983,628$ & $1,744.54$ & 11,455 & & \\
\hline Within batching & $251,998,234$ & $1,150.60$ & 219,015 & & \\
\hline Within zoning & $1,026,203,688$ & 872.66 & $1,175,950$ & & \\
\hline Within routing & $4,739,306$ & $1,754.65$ & 2,701 & & \\
\hline Within storage $\times$ batching & $21,968,749$ & $3,631.04$ & 6,050 & & \\
\hline Within storage $\times$ zoning & $35,904,857$ & $10,579.23$ & 3,394 & & \\
\hline Within storage $\times$ routing & $3,239,644$ & $10,162.15$ & 319 & & \\
\hline Within batching $\times$ zoning & $124,857,632$ & $1,861.94$ & 67,058 & & \\
\hline Within batching $\times$ routing & $9,478,611$ & $1,754.65$ & 5,402 & & \\
\hline Within zoning $\times$ routing & $4,565,966$ & $4,312.63$ & 1,059 & & \\
\hline Total & $1,512,756,826,184$ & $38,962.81$ & & & \\
\hline
\end{tabular}

